\title{
RESPONSES OF PHOTOSYNTHESIS, CHLOROPLAST ULTRASTRUCTURE, AND ANTIOXIDANT SYSTEM OF MORINDA OFFICINALIS HOW. TO EXOGENOUS 2, 4-EPIBRASSINOLIDE TREATMENTS UNDER HIGH TEMPERATURE STRESS
}

\author{
CAI, Y. Q. ${ }^{1,2,4}-$ TARIN, M. W. K. ${ }^{3}-$ FAN, L. L. ${ }^{1}-$ XIE, D. J. ${ }^{1}-$ RoNG, J. D. ${ }^{1}-$ HE, T. Y. ${ }^{3}-$ CHEN, \\ L. G. ${ }^{1}-$ ZHENG, Y. S. ${ }^{1,3^{*}}$ \\ ${ }^{I}$ College of Forestry, Fujian Agriculture and Forestry University, Fuzhou 350002, PR China \\ ${ }^{2}$ College of Biological Sciences and Technology, Minnan Normal University, Zhangzhou \\ 363000, PR China \\ ${ }^{3}$ College of Landscape and Architecture, Fujian Agriculture and Forestry University, Fuzhou \\ 350002, PR China \\ ${ }^{4}$ Fujian Provincial Key Laboratory of Garden Plants with South Fujian Characteristics, Minnan \\ Normal University, Zhangzhou 363000, PR China \\ *Corresponding author \\ e-mail: zys1960@163.com
}

(Received $18^{\text {th }}$ Dec 2019; accepted 27 ${ }^{\text {th }}$ Mar 2020)

\begin{abstract}
The present study attempts to evaluate the effects of EBR (2, 4-epibrassinolide) on photosynthetic parameters, biochemicals, antioxidant systems, and chloroplast ultrastructure in the leaves of Morinda officinalis under high temperature (HT). HT stress significantly reduced the net photosynthetic rate $\left(P_{N}\right)$, stomatal conductance $\left(G_{s}\right)$, and transpiration rate) $\left(T_{r}\right)$, photosynthetic pigments, and inhibited photochemical activity. Besides, the application of EBR alleviated the decrease in chlorophyll contents and the inhibition of photosynthesis induced by HT stress and improved photosystem II efficiency. Furthermore, HT stress markedly increased reactive oxygen species levels and lipid per-oxidation, while the application of $0.5-1.0 \mathrm{mg} \mathrm{L}^{-1} \mathrm{EBR}$ inhibited their increase and enhanced the activity of anti-oxidative enzymes. Microscopic analyses revealed that HT stress induced damages to chloroplasts and thylakoid membranes, displaying chloroplast envelopes disrupted, grana lamellae blurred and stroma lamellar disordered, while $0.5-1.0 \mathrm{mg} \mathrm{L}^{-1}$ EBR treatment effectively protected the thylakoid membrane structure from HT stress, maintained the typical shape of chloroplasts, and promoted the formation of grana. It can be concluded that $0.5-1.0 \mathrm{mg} \mathrm{L}^{-1} \mathrm{EBR}$ can reduce the harmful effects of HT on M. officinalis seedlings by improving photosynthesis and protecting the photosynthetic membrane system from oxidative damage through up-regulating the capacity of antioxidant system.
\end{abstract}

Keywords: photosynthetic parameters, chlorophyll, photosystem II, lipid per-oxidation, thylakoid membrane

\begin{abstract}
Abbreviations: BRs - brassinosteroids; EBR - 2, 4-epibrassinolide; $P_{N}$ - net photosynthetic rate; $G_{s}$ stomatal conductance; $T_{r}$ - transpiration rate; $C_{i}$ - intercellular carbon dioxide concentration; Chl chlorophyll; $C a r$ - carotenoids; $F_{0}$ - minimal fluorescence; $F_{m}$ - the maximum fluorescence; $\mathrm{F}_{\mathrm{v}} / \mathrm{F}_{\mathrm{m}}$ maximal photochemical efficiency; $\Phi_{\text {PSII }}$ - actual photochemical efficiency of PSII; NPQ - nonphotochemical quenching; qP - photochemical quenching; APX - ascorbate peroxidase; CAT - catalase; MDA - malondialdehyde; POD - peroxidase; SOD - superoxide dismutase; GR - glutathione reductase; GSH - reduced glutathione; ROS - reactive oxygen species; $\mathrm{O}_{2}{ }^{-}$- superoxide radical; $\mathrm{H}_{2} \mathrm{O}_{2}$ - hydrogen peroxide; EL - electrolyte leakage; $C h M$ - chloroplast membrane; $S G$ - starch granule; $O S$ - osmiophilic plastoglobuli; $G T$ - grana thylakoid; $S L$ - stroma lamellae; $G L$ - grana lamellae; control - normal temperature with distilled water; HT - high temperature with distilled water; HB1 - high temperature with spraying $0.10 \mathrm{mg} \mathrm{L}^{-1} \mathrm{EBR}$; HB2 - high temperature with spraying $0.50 \mathrm{mg} \mathrm{L}^{-1} \mathrm{EBR}$; HB3 - high temperature with spraying $1.00 \mathrm{mg} \mathrm{L}^{-1} \mathrm{EBR}$
\end{abstract}




\section{Introduction}

Temperature is the most important environmental factor affecting plant growth and development. Excessive temperature is considered to be one of the most severe abiotic stresses restricting plant distribution, growth, and productivity (Jin, 2011; Niu and Wan, 2008). This stress often leads to molecular, biochemical, and physiological modifications which negatively affect the metabolism, reducing the growth and development of plants (Chen et al., 2017; Zhou et al., 2019; Tarin et al., 2020a). Photosynthesis is a key plant physiological process most sensitive to HT stress (Mathur et al., 2014). The thylakoid lamellae of photochemical reaction sites and chloroplast matrix of carbon metabolism sites are the main sites of damage under HT stress (Wise et al., 2010). Photosystem II (PSII) is the most sensitive link to HT during photosynthesis (Crafts-Brandner and Law, 2000). HT not only causes the significant changes in the number, morphology, and structure of organelles such as chloroplasts and mitochondria in plant leaves (Havaux and Tardy, 1996), it also changes the photosynthetic rate by changing the stomatal structure of plant leaves (Zheng et al., 2013), reducing chlorophyll content (Habap et al., 2014) and affecting the electron transfer process of PSII (He et al., 2017; Zushi et al., 2012). Furthermore, HT stress often destroys the balance of reactive oxygen species (ROS) metabolism in plant leaves, causes the accumulation of ROS free radicals, causes membrane lipid peroxidation, protein degeneration, cell membrane damage, resulting the increase of cell membrane permeability or even disintegration, and hindrance in normal metabolism of cells (Khanna-Chopra, 2012; Sedigheh et al., 2011; Silva and Asaeda, 2017). Simultaneously, it also promotes the activities of antioxidant enzymes such as SOD, POD, CAT, APX and the contents of nonantioxidant enzymes such as ASA and GSH to scavenge reactive oxygen species and alleviate the damage of HT stress to plants (Djanaguiraman et al., 2010; Gupta et al., 2013; Wu et al., 2014). In recent past, rise in temperature globally (Hansen et al., 2010; Virginia and Ebi, 2012), many provinces and regions in China have been experiencing prolonged summer with HT (Liu et al., 2015; Peng, 2014), particularly in the vast areas of southern China, which have experienced severe heat waves (Liu et al., 2017; Peng, 2014; Zuo et al., 2016).

Morinda officinalis How. is a vine shrub of Rubiaceae family, mainly grows in tropical and subtropical mountainous areas and forests and is distributed in Fujian, Guangdong, Guangxi, Hainan, and other southern provinces of China (Chen and Taylor, 2011). More than 100 compounds have been isolated from the flesh roots of $M$. officinalis, including anthraquinones, iridoid glycosides, phytosterols, polysaccharides, and oligosaccharides (Chen and Xue, 1987). The compounds extracted from the root of this plant can be used to relieving a wide spectrum of diseases, such as impotence (Wu et al., 2015), osteoporosis (Zhu et al., 2008), depression (Li et al., 2004), rheumatoid arthritis (Shin et al., 2013), dermatitis (Zhang et al., 2013a), and many other diseases. Furthermore, the roots of this plant have long been used as a tonic for kidney and yang, strengthening muscles and bones, eliminating rheumatism, and improving immunity, which has become one of the most common traditional medicines in China and even in Northeast Asia (Zhang et al., 2018). The suitable growth temperature of $M$. officinalis is $20-25^{\circ} \mathrm{C}$, in which the wild growth environment is a shrub or sparse forest edge on a hillside at an altitude of about $300 \mathrm{~m}$ approximately. An increase in the market demand for wood has put enormous pressure on the natural plantation $M$. officinalis. Recently, efforts have been made on the artificial plantation of $M$. officinalis by expanding the planting area in Fujian and Guangdong provinces covering almost 5000 ha in total (Zhang et al., 2016). M. officinalis is normally planted for 5-6 years before the final harvest. Most of the planting areas are low mountains 
and hills with an altitude of 300-700 m and a slope of 20-40 degrees. Previous reports have shown that $M$. officinalis is susceptible to destruction in stem rot resulted from HT stress in summer (Ding and Xu, 2003; Huang, 1982). HT in summer has seriously affected the normal growth and quality of $M$. officinalis. Therefore, there is a need to explore, how to improve the heat tolerance of $M$. officinalis which has become a serious problem in cultivation.

The application of exogenous phytohormones is the most effective and commonly used method to improve plant tolerance under abiotic stress. Brassinosteroids (BRs) are a class of natural products widely existing in plants, which are similar to animal and insect steroids, which have been identified as the sixth major plant hormone regulating plant growth and development (Clouse and Sasse, 1998). Brassinolide is the first BR isolated and identified (Grove et al., 1979). BRs can regulate plant growth (Que et al., 2018), stimulate different plant metabolic processes (Sasse, 2003), reduce oxidative stress, alleviate photosynthesis inhibition, improve plant resistance and yield under adverse conditions, such as drought stress (Lima and Lobato, 2017), high and low-temperature stress (Qu et al., 2011; Zhang et al., 2013b), heavy metal stress (Ramakrishna and Rao, 2013), salt stress (Karlidag et al., 2011), and other biotic or abiotic stresses.2, 4-epibrassinolide (EBR) is a synthetic highactivity analogue of brassinolide. It has been widely used in production because of its good stability and low cost (Bajguz and Hayat, 2009). Zhang et al. (2014) reported that exogenous 2, 4-EBR $\left(0.5-1.5 \mathrm{mg} \mathrm{L}^{-1}\right)$ alleviated the growth inhibition induced by HT stress. $1.0 \mathrm{mg} \mathrm{L}^{-1} 2$, 4-EBR could increase the antioxidant enzyme activity, soluble protein and free proline content of melon under HT stress, and reduce the content of malondialdehyde. Spraying 0.05-0.2 $\mathrm{mg} \mathrm{L}^{-1}$ EBR could improve photosynthetic efficiency and antioxidant enzyme system of eggplant seedlings under HT stress, and inhibit the accumulation of reactive oxygen species and lipid peroxidation (Wu et al., 2014). Pretreatment of Robinia pseudoacacia seeds with $1.04 \mu \mathrm{M} 2$, 4-EBR improved the stability of chloroplast cell membrane and thylakoid membrane, decreased the concentration of sodium ion in leaves, significantly reduced photosynthesis inhibition, and maintained a higher net photosynthetic rate (Yue et al., 2019).

However, BRs-mediated stress response occurs in different tissues, and the mechanism of BRs-induced tolerance is not fully understood. There are few reports about the effect of BRs on heat tolerance of woody plants ( $\mathrm{Li}$ et al., 2018). Therefore, this study aims to investigate the impact of exogenous 2, 4-EBR on chloroplast ultrastructure, gas exchange, chlorophyll fluorescence, and antioxidant system of $M$. officinalis seedlings exposed to HT stress, and to reveal how EBR acting to alleviate HT stress on M. officinalis seedlings.

\section{Materials and methods}

\section{Description of the study area, plant material, and treatments}

The present experiment was started from April to September 2018 in Fujian Agriculture and Forestry University $\left(26^{\circ} 08^{\prime} \mathrm{N}, 11^{\circ} 24^{\prime} \mathrm{E}\right)$, Fujian Province, China. Five-month-old healthy cutting seedlings of $M$. officinalis of uniform size (height: $20 \mathrm{~cm}$ ) were obtained from Nanjing County, Hexi Town, Zhangzhou City, Fujian Province, China. The wellgrowing seedlings of $M$. officinalis were grown in plastic containers $(17 \mathrm{~cm}$ in height and $15 \mathrm{~cm}$ in diameter) in a completely randomized design (Fig. Al in the Appendix), with a mixture of red soil and peat (9:1 volume ratio). Two plants per container were placed in Greenhouse with $60 \%$ to $70 \%$ relative humidity at $28 / 22{ }^{\circ} \mathrm{C}$ (day/night) for 8 weeks. The pre-culturing of cutting seedlings of $M$. officinalis were carried out in the plant incubator 
$(60 \mathrm{~cm} \times 60 \mathrm{~cm} \times 50 \mathrm{~cm})$ under the following controlled conditions; a 12-h photoperiod, the temperature of $28 / 22{ }^{\circ} \mathrm{C}$ (day/night), the photosynthetic photon flux density $600 \mu \mathrm{mol} \mathrm{m} \mathrm{m}^{-2}$ ${ }^{1}$ with 60 to $70 \%$ relative humidity. All plants were irrigated every two days and NPK

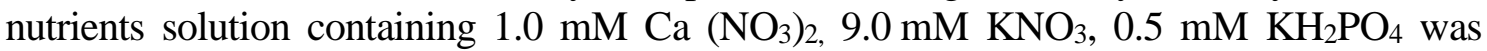
applied once a week.

The 2, 4-epibrassinolide (EBR, sigma, USA) was dissolved in a minimum volume of ethanol and made to be a storage solution with distilled water, stored at $4{ }^{\circ} \mathrm{C}$. Then the storage solution was diluted into the concentrations required for the test with distilled water, and adding tween 20 with a volume ratio of $0.5 \%$ as the surfactant. The EBR and HT treatment started after ten days of pre-culturing. Plants were divided into two groups; normal temperature $\left(28^{\circ} \mathrm{C} / 22^{\circ} \mathrm{C}\right)$ and HT $\left(38^{\circ} \mathrm{C} / 30^{\circ} \mathrm{C}\right)$, before exposure to the HT treatment under the similar condition of a-12 h photoperiod and $600 \mu \mathrm{mol} \mathrm{m} \mathrm{m}^{-2} \mathrm{~s}^{-1}$ photosynthetic photon flux density. Five different treatment combinations were made; (1) normal temperature + distilled water as control, (2) HT + distilled water as HT, (3) $\mathrm{HT}+$ spraying $0.10 \mathrm{mg} \mathrm{L}^{-1} \mathrm{EBR}$ as HB1, (4) $\mathrm{HT}+0.50 \mathrm{mg} \mathrm{L}^{-1} \mathrm{EBR}$ as HB2, and (5) HT $+1.00 \mathrm{mg} \mathrm{L}^{-1} \mathrm{EBR}$ as HB3 (Wu et. al., 2014). The pots were arranged in a completely randomized design with three replicates for each treatment (96 plants) with 480 plants in total for all five treatments. All the plants were sprayed with $25 \mathrm{ml}$ of distilled water or EBR once in every two days. On the third day after spraying (the $10^{\text {th }}$ day under HT stress), leaves from the middle part of plant for each replicate were selected for the measurement of photosynthetic parameters and the third leaf of plant for each replicate from the five treatment were sampled for chloroplast ultrastructure observation, then the others were sampled for determination of chlorophyll contents, ROS and antioxidant systems as described under.

\section{Measurement of gas exchange parameters}

The net photosynthetic rate $\left(P_{N}\right)$, transpiration rate $\left(T_{r}\right)$, stomatal conductance $\left(G_{s}\right)$ and intercellular $\mathrm{CO}_{2}$ concentration $\left(C_{i}\right)$ of the third or fourth fully expanded leaf from the top were measured by using an infrared gas analyzer portable photosynthesis system (LI-6400 XT, LI-COR Inc., Lincoln, NE, USA) from 09:00 to 11:30 h local time as described by Tarin et al. (2019b). During the measurements, the photosynthetic photon flux density was set to $800 \mu \mathrm{mol} \mathrm{m} \mathrm{m}^{-2} \mathrm{~s}^{-1}$, the air relative humidity was from 60 to $70 \%$, the leaf temperature was maintained at $25{ }^{\circ} \mathrm{C}$ and the ambient $\mathrm{CO}_{2}$ concentration was about $400 \mu \mathrm{mol} \mathrm{mol}^{-1}$. Photosynthesis measurement was made once for each leaf and five leaves from different plants per treatment and repeated three times in each treatment.

\section{Determination of chlorophyll fluorescence}

Chlorophyll fluorescence parameters were measured by using a portable pulsemodulated fluorometer (PAM-2500, Walz, Effeltrich, Germany). The data were taken once on the fourth fully expanded leaf of each plant, and six leaves of each treatment were chosen and numbered basipetally. The minimum fluorescence $\left(\mathrm{F}_{0}\right)$ and the maximum fluorescence $\left(\mathrm{F}_{\mathrm{m}}\right)$ induced by a saturation pulse under a weak modulated light were determined after $30 \mathrm{~min}$ of dark adaption. Then the minimum fluorescence $\left(\mathrm{F}_{0}{ }^{\prime}\right)$ and the maximum fluorescence $\left(\mathrm{F}_{\mathrm{m}}\right.$ ')induced by a second saturation pulse in the light-adapted state, and the steady-state fluorescence $\left(\mathrm{F}_{\mathrm{s}}\right)$ were recorded after light adaption at actinic light of $600 \mu \mathrm{mol} \mathrm{m} \mathrm{m}^{-2} \mathrm{~s}^{-1}$. The maximum photochemical quantum yield of PSII $\left(\mathrm{F}_{\mathrm{v}} / \mathrm{F}_{\mathrm{m}}\right)$, the effective photochemical quantum yield of $\operatorname{PSII}\left(\Phi_{\mathrm{PS} \text { II }}\right)$, non-photochemical quenching (NPQ), and 
photochemical quenching ( $\mathrm{qP}$ ) were calculated as the following formula, respectively (Genty et al., 1989; Roháček, 2002).

$$
\begin{aligned}
& \mathrm{F}_{\mathrm{v}} / \mathrm{F}_{\mathrm{m}}=\frac{\mathbf{F}_{\mathrm{m}}-\mathbf{F}_{0}}{\mathbf{F}_{\mathrm{m}}} \\
& \mathrm{NPQ}=\frac{\mathbf{F}_{\mathrm{m}}}{\mathbf{F}_{\mathrm{m}}}, \mathbf{1} \\
& \Phi_{\text {PSII }}=\frac{\mathbf{F}_{\mathrm{m}}{ }^{\prime}-\mathbf{F}_{\mathrm{s}}}{\mathbf{F}_{\mathrm{m}}{ }^{\prime}} \\
& \mathrm{qP}=\frac{\mathbf{F}_{\mathrm{m}}{ }^{\prime}-\mathbf{F}_{\mathrm{s}}}{\mathbf{F}_{\mathrm{m}}{ }^{\prime}-\mathbf{F}_{0}{ }^{\prime}}
\end{aligned}
$$

\section{Estimation of photosynthetic pigment determination}

The photosynthetic pigment concentrations were extracted from $0.2 \mathrm{~g}$ leaves with $80 \%$ acetone $(\mathrm{v} / \mathrm{v})$ in the dark. The absorbance of the extracts was recorded by spectrophotometric measurements at 645, 663, and $470 \mathrm{~nm}$, and the contents of chlorophyll a, chlorophyll b, total chlorophyll, and carotenoids, respectively were calculated according to the methodology of Lichtenthaler (1987).

\section{Determination of ROS production and lipid peroxidation}

The contents of hydrogen peroxide $\left(\mathrm{H}_{2} \mathrm{O}_{2}\right)$ were determined by the absorbance of the peroxide-titanium complex at $410 \mathrm{~nm}$ as described by Patterson et al. (1984). The determination of the superoxide radical $\left(\mathrm{O}_{2}^{-}\right)$production rate was based on the method of Elstner and Heupel (1976). The content of superoxide radical $\left(\mathrm{O}_{2}^{-}\right)$was calculated from the standard curve of nitrite formed from the chemical reaction of hydroxylamine and superoxide radical $\left(\mathrm{O}_{2}^{-}\right)$.

The contents of malondialdehyde (MDA) were measured as described by Guo et al. (2006a) by monitoring the thiobarbituric acid reactive products. Electrolyte leakage was determined by the method of Gong et al. (1998). The electrical conductance value $\left(\mathrm{EC}_{1}\right)$ was measured by inserting the electrode of the conduct meter into the exosmosis solution of leaves samples, then heating at $95^{\circ} \mathrm{C}$ for $20 \mathrm{~min}$ to release the electrolytes. After cooling, the electrical conductance value $\left(\mathrm{EC}_{2}\right)$ was measured again. The percentage of electrolyte leakage was calculated by the following the formula:

$$
\text { Electrolyte leakage }(\%)=\frac{\text { electrical conductance value of fresh sample }}{\text { electrical conductance value of sample cooked }} \times 100
$$

\section{Determination of antioxidant enzyme activity and reduced glutathione (GSH) content}

The activity of superoxide dismutase (SOD) was analyzed by the NBT method of Giannopolitis et al. (1977). One unit of SOD activity is the amount of enzyme required to inhibit the photochemical reduction of nitro blue tetrazolium (NBT) by $50 \%$ at $560 \mathrm{~nm}$. Catalase (CAT) activity was measured according to Havir and Mchale (1987). 
The activity of catalase was defined as the decrease in the absorbance at $240 \mathrm{~nm}$ for 1 min following the consumption of $\mathrm{H}_{2} \mathrm{O}_{2}$.

The activity of ascorbate peroxidase (APX) was determined according to the method of Nakano and Asada (1987) by monitoring the decrease of ascorbate peroxidase and measuring the change in absorbance at $290 \mathrm{~nm}$ for $1 \mathrm{~min}$. Peroxidase activity (POD) was estimated by using the method of Kochba et al. (1977) by following the rate of guaiacol oxidation at $470 \mathrm{~nm}$. The content of reduced glutathione $(\mathrm{GSH})$ and the production rate of glutathione reductase (GR) both were determined by the method given by Foyer and Halliwell (1976).

\section{Determination of free proline and soluble proteins content}

Free proline contents were determined according to the method of Bates et al. (1973) by monitoring the ninhydrin colorimetric reaction. The contents of the total soluble proteins were determined by using the method of Bradford (1976). The absorbance was measured at $595 \mathrm{~nm}$ using bovine serum albumin as a standard.

\section{Observation of chloroplast ultrastructure}

Samples were collected from the middle of the main vein of the third leaf below the apical bud, cut into pieces of $1 \sim 2 \mathrm{~mm}^{2}$. The cut leaves were immediately fixed in a solution containing $3 \%(\mathrm{v} / \mathrm{v})$ glutaraldehyde in a $0.1 \mathrm{~mol} \mathrm{~L}^{-1}$ phosphate buffer $(\mathrm{pH} 7.2$, $4{ }^{\circ} \mathrm{C}$ ) for $2 \mathrm{~h}$ followed by $2 \%(\mathrm{w} / \mathrm{v}$ ) osmium tetroxide in the same buffer for $2 \mathrm{~h}$. After dehydration in a gradient series of ethanol and embedding in Epon 812, ultrathin sections (50 60 nm thick) were made with using an ultramicrotome, then stained with uranium acetate and lead citrate according to the method of Sun et al. (2011), and examined under a Tecnai G2 Spirit Bio Twin transmission electron microscopy (TECNAI, American) at an accelerating voltage of $120 \mathrm{KV}$.

\section{Statistical analysis}

Three replicates were chosen for all biochemical analyses, the data were expressed as the mean \pm standard deviation (SD) with a minimum of three replicates. Statistical analysis was performed by one-way ANOVA with SPSS 17.0 (SPSS, Chicago, USA), the significant differences between the means were determined by using Duncan's multiple range comparison tests at 0.05 level of significance.

\section{Results}

\section{Effects of 2, 4-EBR on the gas exchange parameters under HT stress}

Compared to control treatment, HT stress significantly decreased $P_{N}$ (Fig. 1A), $T_{r}$ (Fig. 1C) and $G_{s}$ (Fig. 1D) by $58.54 \%, 21.60 \%$, and $50.96 \%$ respectively and significantly increased $C_{i}($ Fig. $1 B)$ by $50.42 \%(P<0.05)$. The application of 0.5 $1.0 \mathrm{mgL}^{-1}$ EBR during stress significantly increased $P_{N}$ (Fig. 1A), G $G_{s}$ (Fig. 1C) and $T_{r}$ (Fig. 1D), and significantly decreased $C_{i}$ (Fig. 1B) $(P<0.05)$ compared to HT treatment. The $0.1 \mathrm{mg} \mathrm{L}^{-1}$ EBR also significantly increased $P_{N}, T_{r}$, and decreased $C_{i}$ $(P<0.05)$, but the increase in $G_{s}$ was not significant. The highest $P_{N}\left(3.37 \mu \mathrm{mol} \mathrm{CO}_{2} \mathrm{~m}^{-}\right.$ $\left.{ }^{2} \mathrm{~s}^{-1}\right), G_{s}\left(0.03 \mathrm{~mol} \mathrm{H}_{2} \mathrm{O} \mathrm{m} \mathrm{m}^{-2} \mathrm{~s}^{-1}\right)$ and $T_{r}\left(1.02 \mathrm{mmol} \mathrm{H}_{2} \mathrm{O} \mathrm{m} \mathrm{m}^{-2} \mathrm{~s}^{-1}\right)$, and lowest $C_{i}$ $\left(239.5 \mu \mathrm{mol} \mathrm{CO} \mathrm{Col}^{-1}\right)$ were observed in $\mathrm{HB} 2$ treatment, which were $135.73 \%$, 
$62.57 \%, 61.03 \%$ higher $(P<0.05)$, and $31.20 \%(P<0.05)$ lower than HT treatment, respectively. Whereas the $P_{N}$ and $C_{i}$ under HB2 treatment, no significant difference as compared to control treatment (Fig. 1).
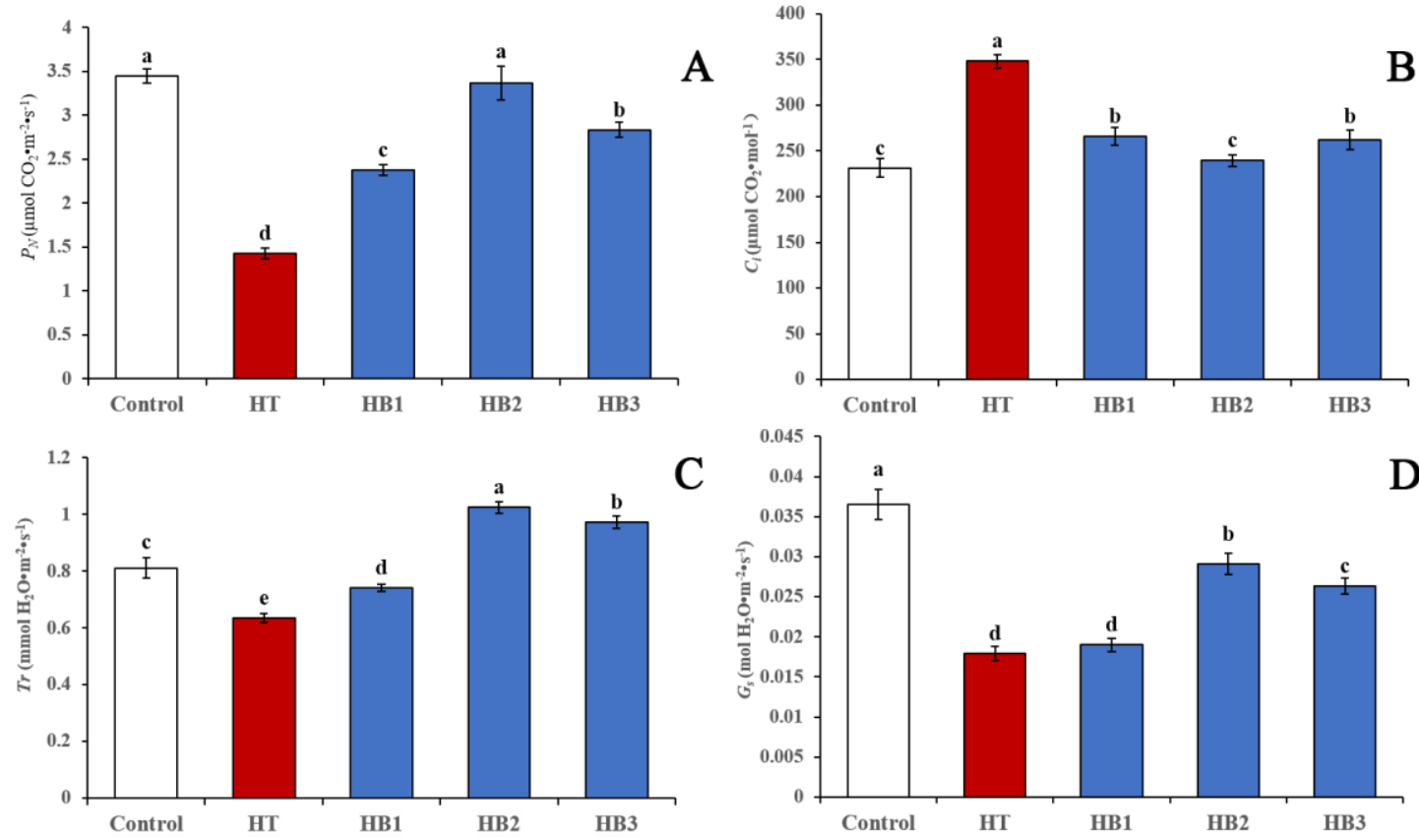

Figure 1. Effects of EBR on gas exchange parameters in leaves of M. officinalis under HT stress. (A) $\mathrm{P}_{\mathrm{N}}$ : Net photosynthetic rate, $(B) \mathrm{C}_{\mathrm{i}}$ : Intercellular carbon dioxide concentration, $(C)$ $\mathrm{T}_{\mathrm{r}}$ : Transpiration rate, $(D) \mathrm{G}_{\mathrm{s}}$ : Stomatal conductance. Treatments include: Control; Normal

temperature with distilled water, HT; High temperature with distilled water, HB1; High temperature with spraying $0.10 \mathrm{mg} \mathrm{L}^{-1}$ EBR, $H B 2$; High temperature with spraying $0.50 \mathrm{mg} \mathrm{L}^{-1}$

$E B R, H B 3$; High temperature with spraying $1.00 \mathrm{mg} \mathrm{L}^{-1}$ EBR. Different letters indicate significant differences $(\mathrm{P}<0.05)$ among various treatments with vertical bars as standard deviations

\section{Effects of 2, 4-EBR on chlorophyll fluorescence parameters under HT stress}

Compared to control treatment, the $\mathrm{F}_{\mathrm{m}}$ (Fig. 2B), $\mathrm{F}_{\mathrm{v}} / \mathrm{F}_{\mathrm{m}}$ (Fig. 2C), $\Phi_{\mathrm{PS} \text { II }}$ (Fig. 2D) and qP (Fig. 2E) of M. officinalis seedlings were significantly decreased by $25.48 \%$, $18.68 \%, 34.86 \%$ and $20.23 \%(P<0.05)$, whereas $\mathrm{F}_{0}$ (Fig. 2A) and NPQ (Fig. 2F) were increased by $25.59 \%$ and $81.35 \%$ respectively $(P<0.05)$ under HT. The application of 0.1-1.0 mg L ${ }^{-1}$ EBR treatments significantly increased $\mathrm{F}_{\mathrm{m}}, \mathrm{F}_{\mathrm{v}} / \mathrm{F}_{\mathrm{m}}, \Phi_{\mathrm{PS} \text { II }}$ and $\mathrm{qP}$ (Fig. $2 B$ E), and decreased $\mathrm{F}_{0}$ (Fig. 2A) and NPQ (Fig. 2F) compared with HT treatment, and HB2 treatment caused the largest increase in $\mathrm{F}_{\mathrm{m}}, \mathrm{F}_{\mathrm{v}} / \mathrm{F}_{\mathrm{m}}, \Phi_{\mathrm{PS} \text { II }}$ and $\mathrm{qP}$ by $21.09 \%$, $20.56 \%, 42.50 \%$ and $18.85 \%(P<0.05)$ respectively, while the biggest decrease in $\mathrm{F}_{0}$ and NPQ by $18.59 \%$ and $43.98 \%(P<0.05)$ than that of HT treatment (Fig. 2).

\section{Effects of 2, 4-EBR on photosynthetic pigments under HT stress}

The contents of chlorophyll a, chlorophyll $b$, total chlorophyll, and carotenoids in leaves of $M$. officinalis seedlings under HT stress were significantly lower than that of control treatment by $40.78 \%, 38.99 \%, 40.33 \%$, and $33.98 \%$, respectively $(P<0.05$; 
Table 1). Application of EBR at $0.1 \sim 1.0 \mathrm{mg} \mathrm{L}^{-1}$ significantly increased the contents of chlorophyll a and chlorophyll $\mathrm{b}$ under HT stress $(P<0.05)$. The effect of different concentrations of EBR treatment on the contents of photosynthetic pigments was different. As compared to the HT treatment, HB2 treatment had the best effect on increasing the contents of chlorophyll a, chlorophyll b, total chlorophyll, and carotenoids by $58.49 \%, 57.62 \%, 58.27 \%$, and $45.30 \%$, respectively $(P<0.05$; Table 1$)$.
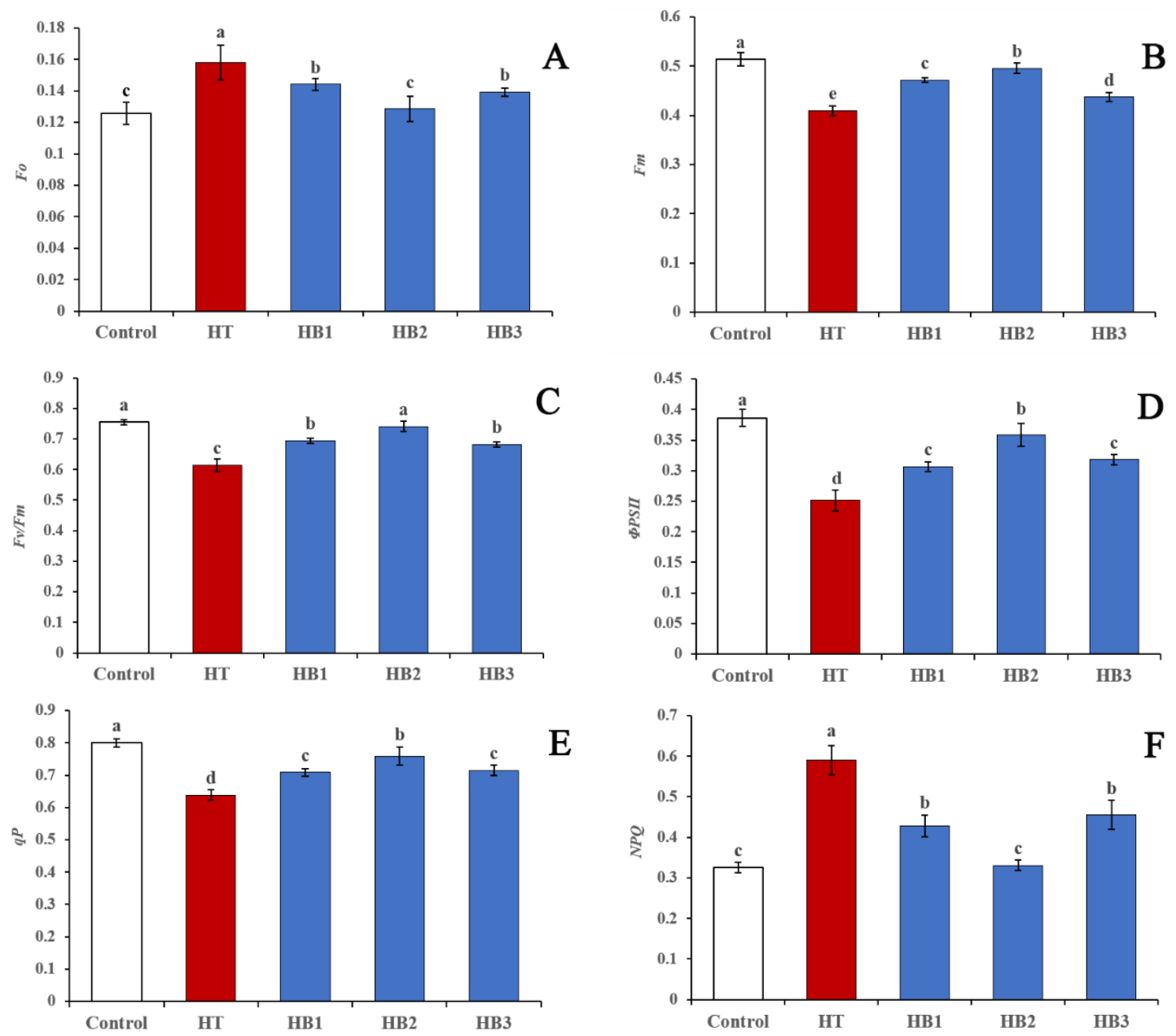

Figure 2. Effects of EBR on chlorophyll fluorescence parameters in leaves of M. officinalis under HT stress. (A) $\mathrm{F}_{0}$ : Minimal fluorescence, $(B) \mathrm{F}_{\mathrm{m}}$ : The maximum fluorescence, $(C) \mathrm{F}_{\mathrm{v}} / \mathrm{F}_{\mathrm{m}}$ : Maximal photochemical, (D) $\Phi_{\mathrm{PSII}}$ : Actual photochemical efficiency of PSII efficiency, (E) $\mathrm{qP}$ : Photochemical quenching, (F) NPQ: Non-photochemical. Treatments include: Control; Normal temperature with distilled water, HT; High temperature with distilled water, HBI; High temperature with spraying $0.10 \mathrm{mg} \mathrm{L}^{-1} E B R$, HB2; High temperature with spraying $0.50 \mathrm{mg} \mathrm{L}^{-1}$

EBR, HB3; High temperature with spraying $1.00 \mathrm{mg} \mathrm{L}^{-1}$ EBR. Different letters indicate significant differences $(\mathrm{P}<0.05)$ among various treatments with vertical bars as standard deviations

\section{Effects of 2, 4-EBR on the producing rate of $\mathrm{O}_{2}^{-}$, contents of $\mathrm{MDA}$ and $\mathrm{H}_{2} \mathrm{O}_{2}$, electrolyte leakage under HT stress}

HT stress caused a remarkable increase in the content of $\mathrm{H}_{2} \mathrm{O}_{2}$ and the rate of $\mathrm{O}_{2}{ }^{-}$ production of $M$. officinalis seedlings by 2.03 and 3.46 times, respectively $(P<0.05)$ 
(Fig. 3A, B), as compared to the control treatment. While the application of 0.1$1.0 \mathrm{mg} \mathrm{L}{ }^{-1}$ EBR significantly reduced the levels of $\mathrm{H}_{2} \mathrm{O}_{2}$ content and $\mathrm{O}_{2}$ - producing rate of $M$. officinalis leaves in the HT stress, and the content of $\mathrm{H}_{2} \mathrm{O}_{2}$ and the rate of $\mathrm{O}_{2}{ }^{-}$ production both contributed u-shaped curves with the increase of EBR concentration (Fig. 3A, B). The lowest levels of $\mathrm{H}_{2} \mathrm{O}_{2}$ content and $\mathrm{O}_{2}{ }^{-}$production rate were observed in HB2 treatment, which was lower than that of HT treatment by $50.49 \%$ and $53.65 \%$, respectively $(P<0.05)$.

Table 1. Photosynthetic pigments in M. officinalis seedlings splayed with EBR under HT stress

\begin{tabular}{c|c|c|c|c}
\hline Treatment & $\begin{array}{c}\text { Chl. } \boldsymbol{a} \\
\left(\mathbf{m g ~ g}^{-\mathbf{1}} \mathbf{F W}\right)\end{array}$ & $\begin{array}{c}\text { Chl. } \boldsymbol{b} \\
\left(\mathbf{m g ~ g}^{-\mathbf{1}} \mathbf{F W}\right)\end{array}$ & $\begin{array}{c}\text { Total Chl } \\
\left(\mathbf{m g ~ g}^{-1} \mathbf{F W}\right)\end{array}$ & $\begin{array}{c}\text { Car. } \\
\left(\mathbf{m g ~ g}^{-\mathbf{1}} \mathbf{F W}\right)\end{array}$ \\
\hline Control & $2.04 \pm 0.037 \mathrm{a}$ & $0.68 \pm 0.017 \mathrm{a}$ & $2.72 \pm 0.022 \mathrm{a}$ & $0.49 \pm 0.011 \mathrm{a}$ \\
HT & $1.21 \pm 0.017 \mathrm{e}$ & $0.42 \pm 0.026 \mathrm{c}$ & $1.62 \pm 0.039 \mathrm{~d}$ & $0.33 \pm 0.007 \mathrm{c}$ \\
HB1 & $1.87 \pm 0.022 \mathrm{c}$ & $0.64 \pm 0.011 \mathrm{a}$ & $2.51 \pm 0.028 \mathrm{~b}$ & $0.43 \pm 0.010 \mathrm{~b}$ \\
HB2 & $1.92 \pm 0.010 \mathrm{~b}$ & $0.65 \pm 0.029 \mathrm{a}$ & $2.57 \pm 0.032 \mathrm{~b}$ & $0.47 \pm 0.007 \mathrm{a}$ \\
HB3 & $1.76 \pm 0.015 \mathrm{~d}$ & $0.52 \pm 0.035 \mathrm{~b}$ & $2.28 \pm 0.021 \mathrm{c}$ & $0.45 \pm 0.013 \mathrm{~b}$ \\
\hline
\end{tabular}

Chl a: Chlorophyll a, Chl b: Chlorophyll b, Total Chl: Total Chlorophyll, Car: Carotenoids. Treatments include: Control; Normal temperature with distilled water, HT; High temperature with distilled water, HB1; High temperature with spraying $0.10 \mathrm{mg} \mathrm{L}^{-1} \mathrm{EBR}$, HB2; High temperature with spraying $0.50 \mathrm{mg} \mathrm{L}^{-1} \mathrm{EBR}$, HB3; High temperature with spraying $1.00 \mathrm{mg} \mathrm{L}^{-1} \mathrm{EBR}$. Different letters indicate significant differences $(P<0.05)$ among various treatments with \pm as standard deviations

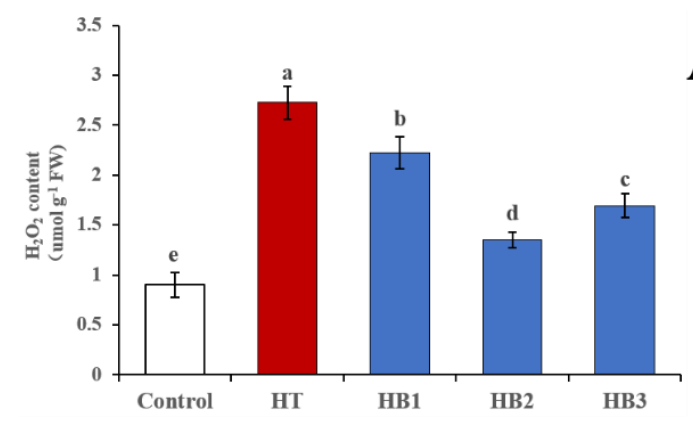

A
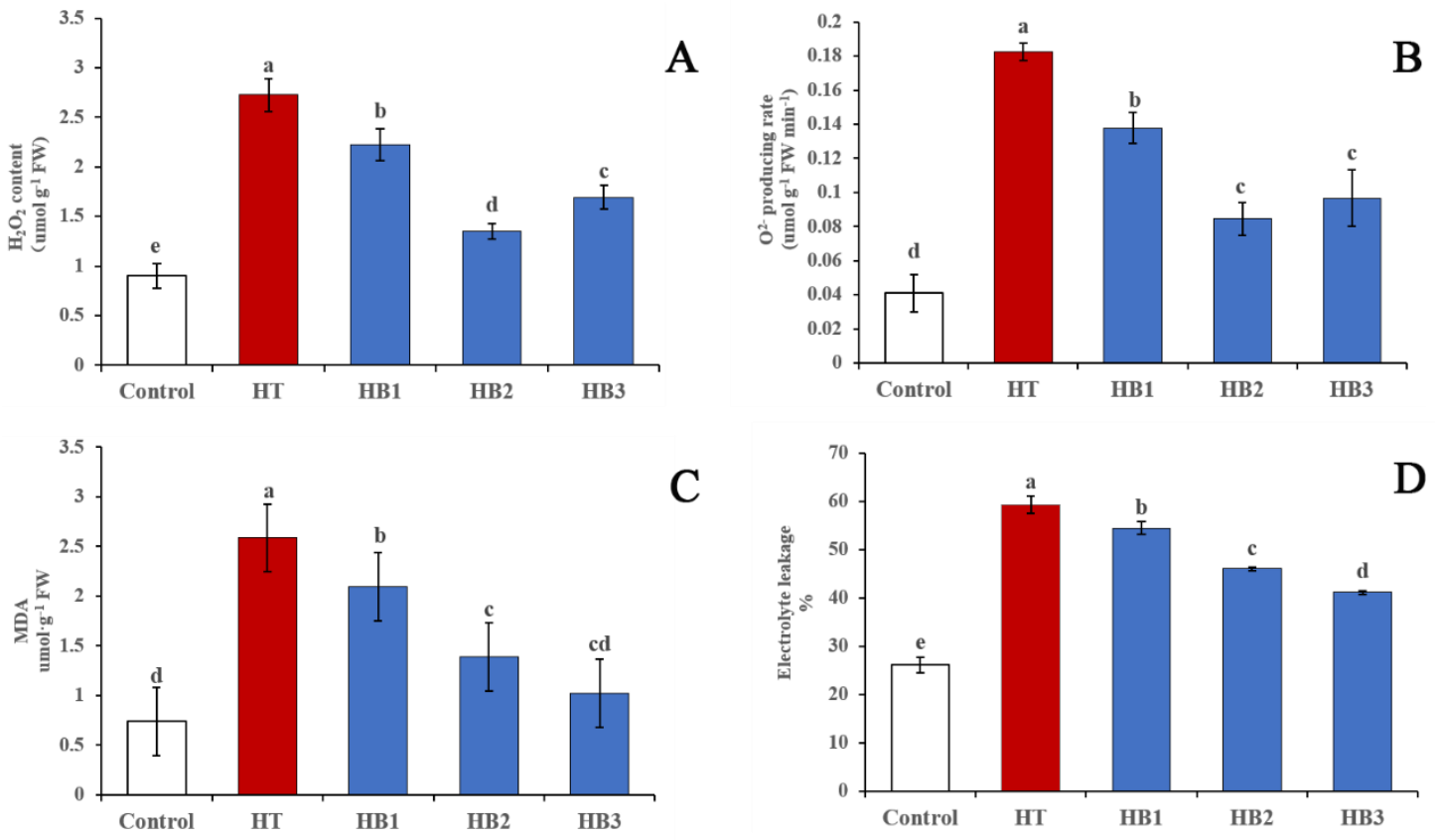

Figure 3. Effects of EBR on (A) Hydrogen peroxide $\left(\mathrm{H}_{2} \mathrm{O}_{2}\right)$ content, $(\mathrm{B})$ Superoxide anion $\left(\mathrm{O}_{2}{ }^{-}\right)$ producing rate, $(C)$ Malondialdehyde (MDA) content, $(D)$ Electrolyte leakage in leaves of $M$. officinalis under HT stress. Treatments include: Control; Normal temperature with distilled water, HT; High temperature with distilled water, HB1; High temperature with spraying

$0.10 \mathrm{mg} \mathrm{L}^{-1} \mathrm{EBR}, \mathrm{HB2}$; High temperature with spraying $0.50 \mathrm{mg} \mathrm{L} \mathrm{L}^{-1} \mathrm{EBR}$, HB3; High temperature with spraying $1.00 \mathrm{mg} \mathrm{L}^{-1}$ EBR. Different letters indicate significant differences $(\mathrm{P}<0.05)$ among various treatments with vertical bars as standard deviations 
Compared with control treatment, HT stress resulted in a significant increase in the MDA content and electrolyte leakage of seedlings by 2.50 and 1.27 times $(P<0.05)$ (Fig. 3C, D), respectively. However, the application of EBR decreased the MDA content and electrolyte leakage of seedlings under stress gradually with the increase of EBR concentration in comparison with HT treatment (Fig. 3C, D). HB3 treatment significantly decreased the MDA content and the electrolyte leakage by $60.46 \%$ and $30.62 \%(P<0.05)$, respectively as compared to HT treatment. Moreover, for MDA contents, no significant difference was observed between HB3, HB2, and control treatment, respectively.

\section{Effects of 2, 4-EBR on the activities of the antioxidant enzyme under HT stress}

HT stress significantly induced the activities of SOD, CAT, POD, APX, and GR by $98.82 \%, 85.70 \%, 67.61 \%, 27.72 \%$, and $89.32 \%$ higher, respectively than that of the control treatment $(P<0.05)($ Fig. $4 A-E)$. Compared with HT treatment, $0.5-1.0 \mathrm{mg} \mathrm{L}^{-1}$ EBR remarkably enhanced the five enzyme activities during stress, while $0.1 \mathrm{mg} \mathrm{L}^{-1}$ EBR treatment significantly increased the activities of CAT, APX, and GR during stress, and had no significant difference on the activities of SOD and POD under HT treatment (Fig. 4A-E). HB2 treatment was found most effective for increasing the activities of SOD, CAT, POD, APX, and GR by 12.56\%, 102.41\%, 68.14\%, 50.01\%, and $116.09 \%$ respectively $(P<0.05)$, as compared to those under HT.

\section{Effects of 2, 4-EBR on reduced glutathione content under HT stress}

The GSH content in leaves of M. officinalis under HT stress increased remarkably by 1.11 times in comparison to control treatment $(P<0.05 ;$ Fig. $4 F)$. Compared with HT treatment, the application of $0.5-1.0 \mathrm{mg} \mathrm{L}^{-1} \mathrm{EBR}$ significantly increased the GSH content under stress, while HB1 treatment showed no influence on the GSH content (Fig. 4F). Moreover, HB2 treatment exhibited the highest increase in the contents of GSH by $99.65 \%(P<0.05)$ higher than that of HT treatment $\left(0.85 \mathrm{mg} \cdot \mathrm{g}^{-1} \mathrm{FW}\right)$, with no significant difference over HB3 treatment.
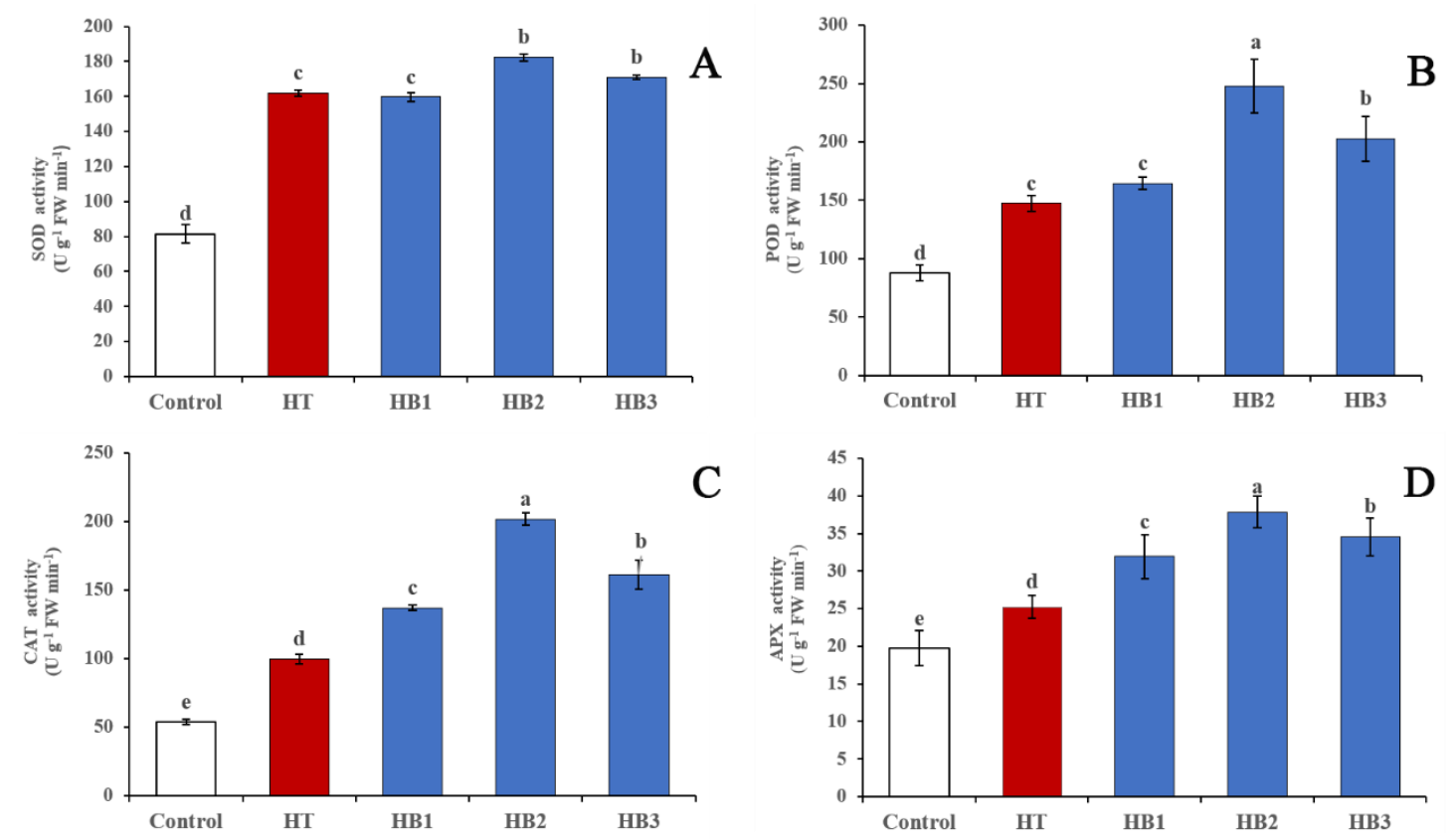

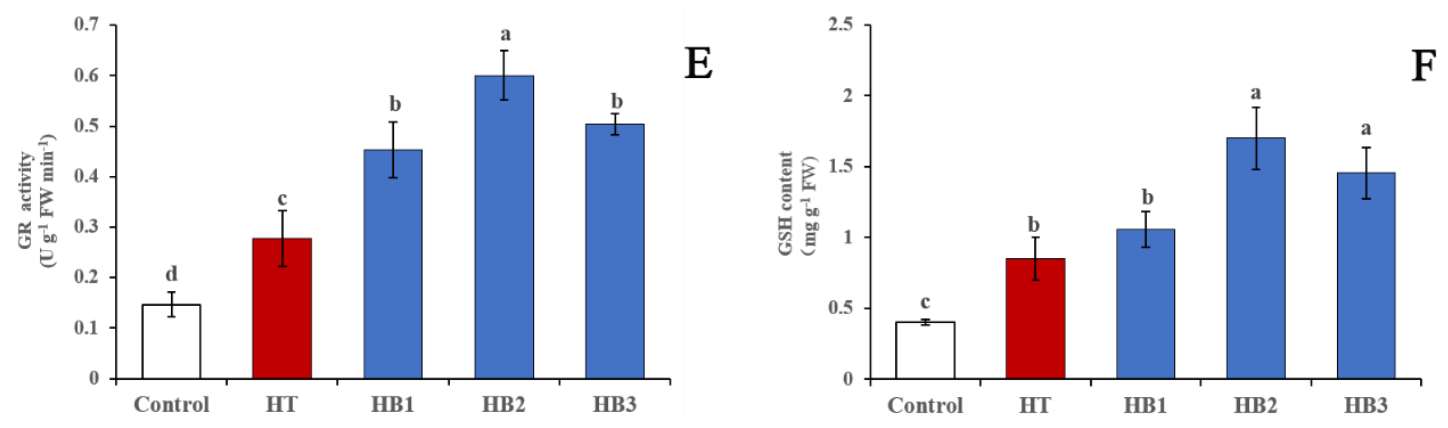

Figure 4. Effects of EBR on activities of (A) Superoxide dismutase (SOD), (B) Peroxidase $(P O D),(C)$ Catalase (CAT), (D) Ascorbate peroxidase (APX), (E) Glutathione reductase (GR), and $(F)$ Contents of reduced glutathione $(G S H)$ in the leaves of M. officinalis under HT stress. Treatments include: Control; Normal temperature with distilled water, HT; High temperature with distilled water, HB1; High temperature with spraying $0.10 \mathrm{mg} \mathrm{L}^{-1}$ EBR, HB2; High temperature with spraying $0.50 \mathrm{mg} \mathrm{L}^{-1} E B R, \mathrm{HB} 3$; High temperature with spraying $1.00 \mathrm{mg} \mathrm{L}^{-1}$ $E B R$. Different letters indicate significant differences $(P<0.05)$ among various treatments with vertical bars as standard deviations

\section{Effects of 2, 4-EBR on the content of proline and soluble protein under HT stress}

Soluble protein content in leaves of $M$. officinalis under HT stress decreased significantly by $22.24 \%$ as compared with the control treatment $\left(208.41 \mu \mathrm{g} \mathrm{g}^{-1} \mathrm{FW}\right)$ $(P<0.05$; Table 2). EBR treatment increased the content of soluble protein under HT stress, but there was no significant difference between EBR treatments for soluble protein contents (Table 2). The soluble protein content at HB2 treatment did not show a more significant difference than that of the control treatment (close to the control level; Table 2). While the proline contents under HT increased 1.24 times in comparison to the control treatment $\left(30.25 \mu \mathrm{g} \mathrm{g}^{-1} \mathrm{FW}\right)(P<0.05)$. Compared with HT treatment, EBR treatment remarkably enhanced the proline content under stress, and with the increase in EBR concentration, the content of proline showed an increasing trend first and then decreased. The maximum accumulation of proline at HB2 treatment $\left(108.39 \mu \mathrm{g} \mathrm{g}^{-1} \mathrm{FW}\right)$ was observed $59.89 \%(P<0.05)$ higher than that of HT treatment $\left(67.79 \mu \mathrm{g} \mathrm{g}^{-1} \mathrm{FW}\right)$.

\section{Effects of 2, 4-EBR on the ultrastructural changes of chloroplasts and thylakoids under HT stress}

The ultrastructure of chloroplast showed thylakoids with grana under control treatment in (Fig. 5A, B). HT stress caused remarkable changes in the ultrastructure of chloroplasts and thylakoids (Fig. 5C, D). Compared with the control, the chloroplasts of high-temperature stress were swollen with increasing the number of plastoglobuli, and chloroplast envelopes partly were destroyed as becoming indistinct. Furthermore, the number of grana lamellae decreased in some chloroplast under stress in comparison to the control, and the thylakoid matrix was swelling with distorted and loosened grana lamellae (Fig. 5C, D). Under HT stress, the chloroplast in mesophyll cells showed no significant swelling, the chloroplast envelope was intact and the fabric of thylakoid lamellar was maintained by applying the EBR (Fig. 5E, F). The chloroplast ultrastructure had no noticeable change under HT by the application of $0.5-1.0 \mathrm{mg} \mathrm{L}^{-1}$ EBR as compared with the control, and the obvious decreased number of plastoglobuli 
and the stacked tightly grana lamellae was observed, as granum were well-arranged and had the smooth thylakoid membranes (Fig. 5F). Most of the chloroplasts maintained the typical shape at $0.1 \mathrm{mg} \mathrm{L}^{-1}$ EBR treatment under stress, while few thylakoid grana lamellae were slightly swollen and the number of plastoglobuli were much more than that of the control (Fig. 5E).

Table 2. Content of proline and soluble protein in M. officinalis seedlings splayed with EBR under HT stress

\begin{tabular}{c|c|c}
\hline Treatment & $\begin{array}{c}\text { Proline content } \\
\mu \mathbf{g ~ g}^{-\mathbf{1}} \mathbf{F W}\end{array}$ & $\begin{array}{c}\text { Soluble protein content } \\
\boldsymbol{\mu} \mathbf{g ~ g}^{-\mathbf{1}} \mathbf{F W}\end{array}$ \\
\hline Control & $30.25 \pm 1.44 \mathrm{~d}$ & $208.41 \pm 10.83 \mathrm{a}$ \\
HT & $67.79 \pm 4.22 \mathrm{c}$ & $162.05 \pm 9.33 \mathrm{c}$ \\
HB1 & $80.22 \pm 5.85 \mathrm{~b}$ & $173.62 \pm 14.92 \mathrm{bc}$ \\
HB2 & $108.39 \pm 9.24 \mathrm{a}$ & $191.74 \pm 5.15 \mathrm{ab}$ \\
HB3 & $89.81 \pm 7.49 \mathrm{~b}$ & $183.49 \pm 6.97 \mathrm{~b}$ \\
\hline
\end{tabular}

Treatments include: Control; Normal temperature with distilled water, HT; High temperature with distilled water, HB1; High temperature with spraying $0.10 \mathrm{mg} \mathrm{L}^{-1} \mathrm{EBR}$, HB2; High temperature with spraying $0.50 \mathrm{mg} \mathrm{L}^{-1}$ EBR, HB3; High temperature with spraying $1.00 \mathrm{mg} \mathrm{L}^{-1}$ EBR. Different letters indicate significant differences $(P<0.05)$ among various treatments with \pm as standard deviations
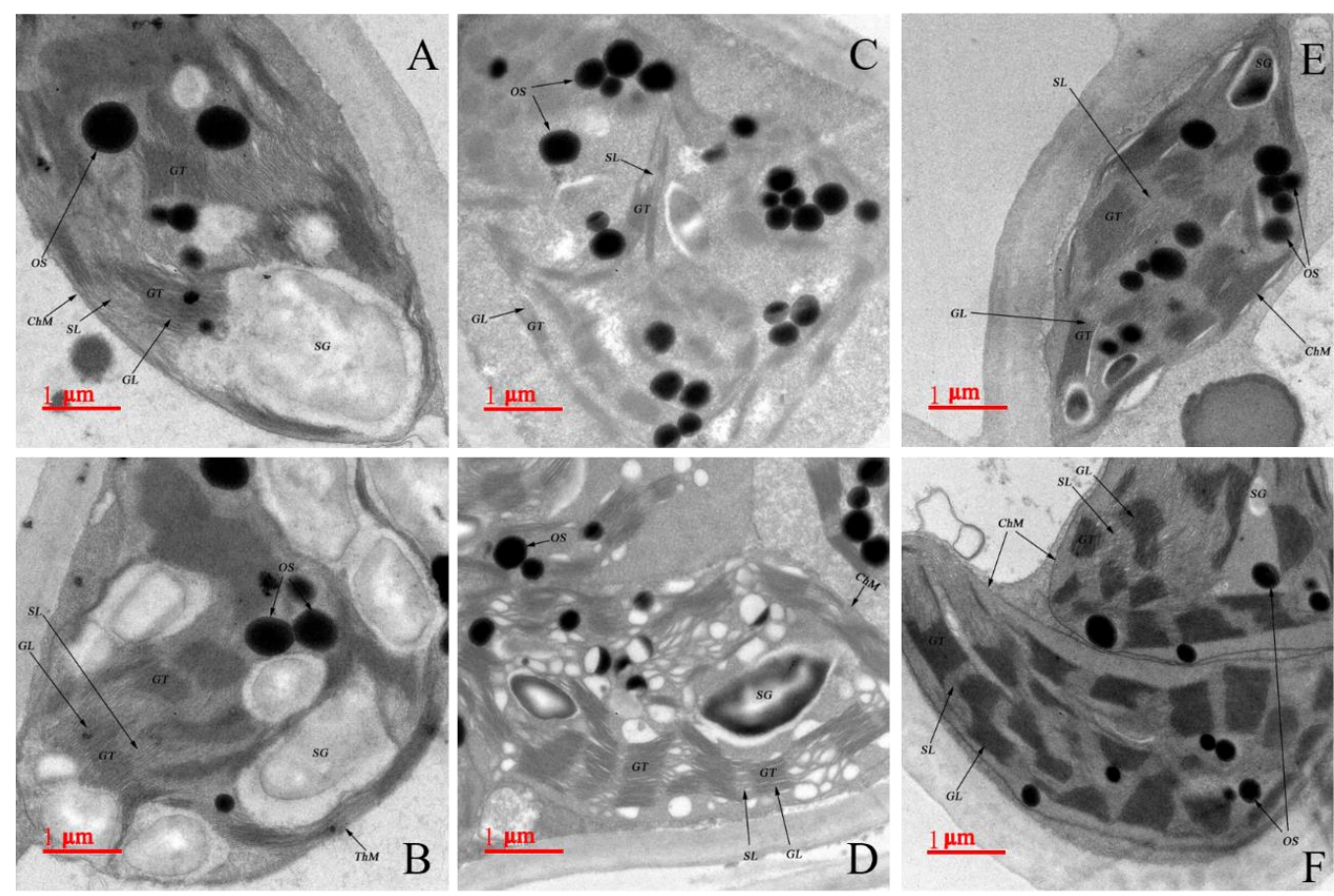

Figure 5. Effects of HT on the ultrastructure of chloroplasts and thylakoids in the leaves of $M$. officinalis with or without EBR treatment. (A, B) The ultrastructure of chloroplasts and thylakoids under control treatment, $(C, D)$ The ultrastructure of chloroplasts and thylakoids under high temperature treatment, $(E)$ The ultrastructure of chloroplasts and thylakoids under high temperature with spraying $0.10 \mathrm{mg} \cdot \mathrm{L}^{-1} E B R,(F)$ The ultrastructure of chloroplasts and thylakoids under high temperature with spraying $0.50 \mathrm{mg} \cdot L^{-1} E B R$, ChM: Chloroplast membrane, SG: Starch granule, OS: Osmiophilic plastoglobuli, GT: Grana thylakoid, SL:

Stroma lamellae, GL: Grana lamellae 


\section{Discussion}

Numerous studies have shown that the application of exogenous 2, 4-EBR can regulate various physiological metabolic processes in plants and improve the stress resistance including abiotic stresses such as drought stress (Lima and Lobato, 2017), salt stress (Yue et al., 2019), flood stress (Wang et al., 2015), high or low-temperature stress (El-Bassiony et al., 2012; Shu et al., 2016). However, reports that contain the effects of 2, 4-EBR on the woody plant are scant. Wang et al. (2015) pointed out that the application of exogenous EBR protected the photosynthetic organelles of grape leaves from the adverse effects of water stress, and increased chlorophyll content, and reduced the limitation of stomatal and non-stomatal photosynthesis. Whereas Yue et al. (2019) observed that pretreatment of locust seeds and seedlings with exogenous 2, 4-EBR enhanced the activity of antioxidant system in leaves of locust seedlings under salt stress, stabilized chloroplast and thylakoid membrane ultrastructure, and related effects on sodium ion concentration and photosynthetic gas exchange parameters in leaves. In our study, it was found that appropriate concentration of exogenous EBR effectively enhanced the photosynthetic characteristics of $M$. officinalis leaves, reduce oxidative damage and protect the chloroplast ultrastructure of mesophyll in plants when subjected to HT stress.

HT stress inhibits the photosynthesis process by decreasing the photosynthetic rate and reducing light energy conversion efficiency. According to Farquhar et al. (1982), the decrease of photosynthetic rate may be contributed to stomatal or non-stomatal limitation, when the decrease of $P_{N}$ is mainly caused by stomatal limitation, $G_{s}$ and $C_{i}$ decrease simultaneously, when the decrease of $P_{N}$ is mainly caused by non-stomatal limitation, $C_{i}$ increases or remains constant accompanied with a decrease in $G_{s}$. In this study, HT stress reduced $P_{N}$ of plants without EBR treatment in parallel with decreased $G_{s}$ and increased $C_{i}$, suggesting that HT stress affected non-stomatal limitation (Fig. 1A$D)$. While EBR treatment alleviated the decline of $P_{N}$ and $G_{s}$ in plants under HT stress and promoted the decrease of $C_{i}$ and the increase of $T_{r}$ at the same time (Fig. 1A-D), which is consistent with the results of Thussagunpanit et al. (2015b) and Zhang et al. (2014). It is possible that EBR treatment can mitigate the non-stomatal limitation to photosynthesis, increase the activity of Rubisco (Xia et al., 2009), and the absorption capacity of $\mathrm{CO}_{2}$ in the Calvin cycle (Zhao et al., 2017) under HT. Meanwhile, the increase of $G_{s}$ and $T_{r}$ in EBR-treated plants may decrease the leaf temperature (Singh and Shono, 2005), which helps to reduce the damage from HT stress and maintain a high photosynthetic rate.

Studies have shown that HT stress accelerated the degradation of chlorophyll and inhibited the biosynthesis of chlorophyll, resulted in the reduction of chlorophyll content (Aien et al., 2011). In our study, HT stress significantly reduced chlorophyll a, chlorophyll b, total chlorophyll content and carotenoid content in leaves, while EBR treatment increased photosynthetic pigments content of $M$. officinalis seedlings (Table 1), which is similar to the previous studies (Thussagunpanit et al., 2015a; Zhang et al., 2013b). The possible reason is that EBR enhances the antioxidant enzyme system, effectively eliminates the accumulation of reactive oxygen species, and reduces the damage of membrane lipid peroxidation products (MDA) to chloroplast membrane (Lima and Lobato, 2017), promotes the biosynthesis of chlorophyll (Eriko et al., 2014). This indicated that EBR with appropriate concentration could alleviate the damage of HT to the chloroplast of plants, enhance the ability of light capture, lessen the nonstomatal limitation of HT on net photosynthetic rate, and improve photosynthesis effectively, which is in the line with studies of Cucumis sativus (Fariduddin et al., 
2013). Carotenoids are considered to be used as antioxidants to resist lipid peroxidation, reduce the fluidity of thylakoid membranes, and increase the stability of membranes (Tang et al., 2007). Besides, the increase of the carotenoids contents helps to eliminate the accumulation of excess excitation energy, thus playing the role of photoprotection (Calatayud and Barreno, 2004).

Chlorophyll fluorescence is a subtle reflection of the primary response of photosynthesis. It is widely used to study the effect of environmental stress on photosynthesis (Sayed, 2003). In our study, the maximum photochemical efficiency of PSII as $\mathrm{F}_{\mathrm{v}} / \mathrm{F}_{\mathrm{m}}$, the effective photochemical quantum yield of PSII as $\Phi_{\mathrm{PSII}}$, and photochemical quenching of PSII as qP in $M$. officinalis leaves significantly decreased in response to HT stress (Fig. 2C-E). However, EBR-treated plants showed the less decrease in $\mathrm{F}_{\mathrm{v}} / \mathrm{F}_{\mathrm{m}}$ ratio under HT (Fig. 2C), suggesting that exogenous EBR can alleviate the damage of HT to PSII reaction center, which may be because of exogenous EBR which improves the conversion efficiency of PSII primary light energy and reduces photosynthesis inhibition (Maxwell and Johnson, 2000; Zhang et al., 2014). Correspondingly, the changes pattern of $\Phi_{\mathrm{PS} \text { II }}$ and $\mathrm{qP}$ are similar to those of $\mathrm{F}_{\mathrm{v}} / \mathrm{F}_{\mathrm{m}}$ (Fig. 2C-E). Under HT, EBR treatment induced the increase of $\Phi_{\mathrm{PS} \text { II }}$ (Fig. 2D), indicating that exogenous EBR promotes an enhancement of the carboxylation efficiency caused by downstream regulation mechanism (Zhang et al., 2014). The increase in $\mathrm{qP}$ suggested that an improvement in the rate of reductant consumption and ATP formation by noncyclic electron transport relative to the excitation rate of the open PSII reaction center (Nogués and Baker, 2000). Whereas, the increase in $\mathrm{qP}$ is conducive to the separation of electron charges in the reaction center to obtain a higher photochemical quantum yield of PSII and electron transfer rate (Guo et al., 2006b). NPQ is photochemical quenching of PSII, representing the energy absorbed by PSII antenna pigments which could not be used for energy dissipation of electron transfer in photochemistry (Vasil'Ev et al., 1998). The increase of NPQ in EBR treated plants with varying degrees under HT was smaller than that of untreated plants under HT stress (Fig. $2 F$ ), suggesting that the application of EBR protected the PSII reaction center, with accelerating the rate of photosynthetic electron transfer and reducing heat dissipation of excitation energy in PSII antenna under HT (Zhang et al., 2013b). Similar findings were observed by Ogweno et al. (2008) and Janeczko et al. (2011) both that EBR treatment could protect PSII against over-excitation and from the damage of thylakoid membrane induced by HT.

HT stress affects the utilization and transformation of light energy in plant leaves. Surplus light energy is converted to the excitation energy of Mehler reaction, and the improvement of the reaction of photosynthetic electron transfer in branch with molecular oxygen as its receptor, which accelerates the production of reactive oxygen species and destroys the dynamic balance between reactive oxygen species accumulation and antioxidant defense system in plants, and leads to the accumulation of reactive oxygen species (Grennan and Ort, 2007). Accumulation of reactive oxygen species (ROS) causes lipid peroxidation and electrolyte leakage, affecting the normal physiological function of cells. MDA is one of the end products of membrane lipid peroxidation which binds with proteins and enzymes on the membrane, resulting in the destruction of membrane integrity and loss of selective permeability, and increase of conductivity (Anjum et al., 2016). It has been further explained that exogenous EBR could induce the expression of related regulatory genes involved in defense and antioxidant response, thus increasing the tolerance of plants to oxidative stress and 
alleviating the damage of stress to cells (Wu et al., 2014). In our study, HT caused a significant increase of $\mathrm{O}_{2}^{-}$production rate and $\mathrm{H}_{2} \mathrm{O}_{2}$ content in $M$. officinalis leaves (Fig. 3A, B), accelerated the accumulation of membrane lipid peroxide MDA and led to an increase in MDA content and electrolyte leakage (Fig. 3C, D), which indicates that HT had induced oxidative stress to M. officinalis.

An active oxygen scavenging system plays an important role in protecting cells from photooxidation damage (Mittler, 2002). In our study, HT increased the activities of SOD, POD, APX, CAT, and GR in M. officinalis leaves (Fig. 4A-E), and EBR treatment further enhanced the activities of these five enzymes and also reduced the production rate of $\mathrm{O}_{2}{ }^{-}$and $\mathrm{H}_{2} \mathrm{O}_{2}$ content, MDA content and electrolyte leakage in the leaves of M. officinalis seedlings under HT stress (Fig. 3A-D). Recently, many studies have shown that EBR plays an important role in activating antioxidant defense system and scavenging reactive oxygen species under abiotic stresses. Limal et al. (2017) reported that EBR treatment significantly reduced the MDA content and electrolyte leakage in cowpea plants under drought stress, which could be attributed to the application of EBR to increase SOD, POD, APX and CAT activities under stress, and to reduce the rate of $\mathrm{O}_{2}{ }^{-}$production and $\mathrm{H}_{2} \mathrm{O}_{2}$ content. Arora et al. (2010) also showed that MDA contents in mustard leaves treated with EBR decreased significantly under zinc stress, while the activities of antioxidant enzymes (SOD, CAT, POD, APX, GR, MDhar and Dhar) increased significantly. The increase in activities of antioxidant enzymes after EBR treatment might be due to BR induces de novo synthesis or activate the enzymes mediated through transcription or translation of specific genes (Bajguz, 2000).

GSH is one of the important non-enzymatic antioxidants in the ASA-GSH cycle, which plays an important role in protecting plants from ROS damage (Yuan et al., 2013). EBR regulates the activities of antioxidant enzymes (APX, GR) involved in the ASA-GSH cycle, improves the circulation ability of ASA-GSH, and reduces oxidative stress damage (Yuan et al., 2013). Wu et al. (2014) described that exogenous EBR increased the content of non-enzymatic antioxidants ASA and GSH in the leaves of eggplant plants under the HT stress, and inhibited the production of free radicals and membrane lipid peroxidation, thereby enhancing the tolerance of plants to HT stress. In this study, $0.5 \mathrm{mg} \mathrm{L}^{-1}$ EBR significantly enhanced GR and APX activities in the leaves of M. officinalis under HT stress, increased GSH content, and enhanced the ability of scavenging ROS (Fig. 4F). Our results indicated that the application of EBR could eliminate ROS in time by increasing the activity of antioxidant enzymes and the content of non-enzymatic antioxidants, reduction in the damage of reactive oxygen species to the membrane, maintained the integrity and stability of the membrane structure and improved the resistance of $M$. officinalis seedling to HT oxidative stress.

Under abiotic stress, proline largely accumulates in plants as an important membrane stabilizer and scavenger of harmful free radicals, which plays an important role in protecting cell membranes, stabilizing protein structure, and improving cell water retention (Shamsul et al., 2012). However, abiotic stress has a negative impact on the protein biosynthesis of plants (Wahid et al., 2007). In our study, seedlings subjected to HT stress showed increased proline content and decreased protein content (Table 2) which was also reported in Cucumis melo under HT stress by Zhang et al. (2014). Moreover, 0.5-1.0 mg L ${ }^{-1}$ EBR treatment further increased proline contents and enhanced the accumulation of soluble protein of the leaves under HT stress (Table 2). $\mathrm{Wu}$ et al. (2014) indicated that the application of $0.05-0.2 \mu \mathrm{M}$ EBR significantly increased the contents of proline and soluble protein in eggplant under HT stress. EBR 
application enhances the accumulation of proline may be attributed to stimulate the activity of delta-pyrrolidine-5-carboxylate synthase (a key enzyme in proline biosynthesis pathway) or inhibit the activity of proline dehydrogenase, thus promoting the biosynthesis of proline or enhancing the accumulation of proline. The increase in soluble protein contents in the present study might be due to EBR inducing or activating de novo polypeptide synthesis (Ramakrishna and Rao, 2012). Kulaeva et al. (1991) had earlier proposed that EBR activated the synthesis of protein in wheat leaves under HT stress, also improved the anti-stress ability of the protein synthesis system and the characteristics of the cell membrane. It seems to believe that EBR can induce plants to increase the accumulation of different compatible solutes to protect plants from oxidative damage caused by HT stress.

Chloroplasts are not only the main sites of photosynthesis, energy flow in plants, but also one of the most sensitive organelles to stress (Stoyanova and Yordanov, 2000). Studies have shown that oxidative stress induced by stress often leads to oxidative damage of organelles (Djanaguiraman et al., 2018). Austin et al. (2006) reported that the numbers of osmiophilic granules in chloroplasts were in dynamic equilibrium at normal temperature, lipids accumulated in thylakoid membranes, and released into plastoglobuli with the increase of temperature. Almeida et al. (2005) also indicated that the number of osmiophilic precipitates increased in chloroplasts of plants treated with hydrogen oxide. Yue et al. (2019) found that salt stress not only induced oxidative stress to Robinia pseudoacacia seedlings but also resulted in swelling of chloroplast and rupture of the thylakoid membrane in leaves. In this study, microscopic analysis showed that HT stress led to the chloroplast swelling, and some thylakoid grana lamellae became swollen and loosened as the number of osmiophilic granules increased (Fig. 5C, D), suggesting that HT stress had destroyed chloroplasts and thylakoids, which is consistent with the results of Djanaguiraman et al. (2018) in response to HT stress in wheat. Zhang et al. (2010) demonstrated that the oxidation of membrane lipids in chloroplasts or thylakoids induced by ROS resulted in the formation of osmiophilic granules, the size and number of them involved in the degree of membrane lipid peroxidation in chloroplasts.

The thylakoid membrane is the place of light-dependent reaction in photosynthesis, where chlorophyll is mainly located (Mathur et al., 2014). It is more sensitive to HT than chloroplast membrane or other organelles (Sayed et al., 1989), as the damage of HT stress occurring would lead to the degradation of chlorophyll and the decrease of photosynthetic rate (Jumrani et al., 2017). Almeida et al. (2005) reported that exogenous homobrassinolide increased the activities of antioxidant enzymes in potato plants under the condition of $100 \mathrm{mM} \mathrm{H}_{2} \mathrm{O}_{2}$ treatment, and significantly lowered the negative effects of $\mathrm{H}_{2} \mathrm{O}_{2}$ on mesophyll subcellular structure of the plants, with restoring the affected cell structure and reducing the symptoms of leaf injury. Our results showed that exogenous EBR alleviated the degradation of chloroplast subjected to HT (Fig. 5E, F). In particular, under HT stress the application of $0.5 \mathrm{mg} \mathrm{L}^{-1} \mathrm{EBR}$ was beneficial to keep the integrity of chloroplast ultrastructure and normalize the overall morphology of thylakoids in chloroplasts (Fig. 5F), as promoting the synthesis of chlorophyll and maintaining the structural integrity and relative stability of photosynthetic membrane system (Dobrikova et al., 2014; Yue et al., 2019). This could be explained by the fact that exogenous EBR protected the photosynthetic membrane system from oxidative damage caused by HT stress through improving the antioxidant system and reducing lipid peroxidation. Simultaneously, it was confirmed with the decrease in $\mathrm{H}_{2} \mathrm{O}_{2}$ and MDA contents in $M$. officinalis plants treated EBR under HT stress. 


\section{Conclusion}

In conclusion, exogenous EBR reduced the inhibition of photosynthesis of $M$. officinalis seedlings under HT stress, enhanced antioxidant system and the content of photosynthetic pigments, decreased the accumulation of reactive oxygen species and the degree of membrane lipid peroxidation, stabilized the membrane's structure of chloroplast and thylakoid, and alleviated the oxidative damage of heat stress to the photosynthetic apparatus. EBR also had a dose-effect on alleviating the adverse effects of HT stress on $M$. officinalis seedlings, and EBR at $0.5 \mathrm{mg} \mathrm{L}^{-1}$ was the best concentration. However, further research is needed to focus on the elucidation of EBRinduced thermotolerance on molecular levels of plants that how EBR enhances the accumulation of heat-shock proteins and affects the transcriptional level of heat-shock proteins genes.

Acknowledgments. This work was funded by Young and Middle-aged Teacher Education Research Foundation of Fujian Education Department (JAT170359), Modern Seed Industry Development Foundation of Zhang Zhou city in Fujian Province (201842), The Science and Technology Innovation Foundation of Fujian Agriculture and Forestry University (CXZX2017497), and Fujian Provincial Key Laboratory of Garden Plants with South Fujian Characteristics Construction Funds in Fujian Province, China.

\section{REFERENCES}

[1] Aien, A., Khetarpal, S., Pal, M. (2011): Photosynthetic characteristics of potato cultivars grown under HT. - American-Eurasian J Agric \& Environ Sci 11: 633-639.

[2] Almeida, J. M., Fidalgo, F., Confraria, A., Santos, A., Pires, H., Santos, I. (2005): Effect of hydrogen peroxide on catalase gene expression, isoform activities and levels in leaves of potato sprayed with homobrassinolide and ultrastructural changes in mesophyll cells. Functional Plant Biology 32: 707-720.

[3] Anjum, S. A., Tanveer, M., Hussain, S., Shahzad, B., Ashraf, U., Fahad, S., Hassan, W., Jan, S., Khan, I., Saleem, M. F. (2016): Osmoregulation and antioxidant production in maize under combined cadmium and arsenic stress. - Environmental Science \& Pollution Research 23: 11864-11875.

[4] Arora, P., Bhardwaj, R., Kanwar, M. K. (2010): 24-epibrassinolide induced antioxidative defense system of Brassica juncea L. under Zn metal stress. - Physiology \& Molecular Biology of Plants 16: 285-293.

[5] Austin, J., Frost, E., Vidi, P., Kessler, F., Staehelin, L. (2006): Plastoglobules are lipoprotein subcompartments of the chloroplast that are permanently coupled to thylakoid membranes and contain biosynthetic enzymes. - Plant Cell 18: 1693-1703.

[6] Bajguz, A. (2000): Effect of brassinosteroids on nucleic acids and protein content in cultured cells of Chlorella vulgaris. - Plant Physiology \& Biochemistry 38: 209-215.

[7] Bajguz, A., Hayat, S. (2009): Effects of brassinosteroids on the plant responses to environmental stresses. - Plant Physiol Biochem 47: 1-8.

[8] Bates, L. S., Waldren, R. P., Teare, I. D. (1973): Rapid determination of free proline for water-stress studies. - Plant \& Soil 39: 205-207.

[9] Bradford, M. M. (1976): A rapid and sensitive method for the quantitation of microgram quantities of protein utilizing the principle of protein-dye binding. - Analytical Biochemistry 72: 248-254. 
[10] Calatayud, A., Barreno, E. (2004): Response to ozone in two lettuce varieties on chlorophyll fluorescence, photosynthetic pigments and lipid peroxidation. - Plant Physiology \& Biochemistry Ppb 42: 549-555.

[11] Chen, T., Taylor, C. M. (2011): Flora of China. -Science Press, Beijing, pp. 226-227.

[12] Chen, Y. E., Zhang, C. M., Su, Y. Q., Ma, J., Zhang, Z. W., Yuan, M., Zhang, H. Y., Yuan, S. (2017): Responses of photosystem II and antioxidative systems to high light and HT co-stress in wheat. - Environmental \& Experimental Botany 135: 45-55.

[13] Chen, Y. W., Xue, Z. (1987): Chemical constituents of M. officinalis How. - Bulletin of Traditional Chinese Medicine 12: 39-40.

[14] Clouse, S. D., Sasse, J. M. (1998): Brassinosteroids: essential regulators of plant growth and development. - Annual Review of Plant Physiology \& Plant Molecular Biology 49: 427.

[15] Crafts-Brandner, S. J., Law, R. D. (2000): Effect of heat stress on the inhibition and recovery of the ribulose-1,5-bisphosphate carboxylase/oxygenase activation state. Planta 212: 67-74.

[16] Ding, P., Xu, H. (2003): Effects of cultivation conditions on active ingredients of $M$. officinalis. - Journal of Chinese Medicinal Materials 26: 621-622.

[17] Djanaguiraman, M., Prasad, P. V. V., Seppanen, M. (2010): Selenium protects sorghum leaves from oxidative damage under HT stress by enhancing antioxidant defense system. - Plant Physiology \& Biochemistry 48: 999-1007.

[18] Djanaguiraman, M., Boyle, D. L., Welti, R., Jagadish, S. V. K., Prasad, P. V. V. (2018): Decreased photosynthetic rate under HT in wheat is due to lipid desaturation, oxidation, acylation, and damage of organelles. - BMC Plant Biology 18: 55.

[19] Dobrikova, A. G., Vladkova, R. S., Rashkov, G. D., Todinova, S. J., Krumova, S. B., Apostolova, E. L. (2014): Effects of exogenous 24-epibrassinolide on the photosynthetic membranes under non-stress conditions. - Plant Physiology \& Biochemistry Ppb 80: 7582.

[20] El-Bassiony, A. M., Ghoname, A. A., El-Awadi, M. E., Fawzy, Z. F., Gruda, N. (2012): Ameliorative effects of brassinosteroids on growth and productivity of snap beans grown under HT. - Gesunde Pflanzen 64: 175-182.

[21] Elstner, E. F., Heupel, A. (1976): Inhibition of nitrite formation from hydroxylammoniumchloride: a simple assay for superoxide dismutase. - Analytical Biochemistry 70: 616-620.

[22] Eriko, Y., Mai, K., Ayumi, Y., Mieko, H. T., Minami, M., Yusuke, K., Yukihisa, S., Masaaki, S., Hiroyuki, O., Tadao, A. (2014): BPG3 is a novel chloroplast protein that involves the greening of leaves and related to brassinosteroid signaling. - Bioscience Biotechnology \& Biochemistry 78: 420-429.

[23] Fariduddin, Q., Khalil, R. R. A. E., Mir, B. A., Yusuf, M., Ahmad, A. (2013): 24Epibrassinolide regulates photosynthesis, antioxidant enzyme activities and proline content of Cucumis sativus under salt and/or copper stress. - Environmental Monitoring \& Assessment 185: 7845-7856.

[24] Farquhar, G. D., Sharkey, T. D. (1982): Stomatal conductance and photosynthesis. Annual Review of Plant Physiology 33: 317-346.

[25] Foyer, C. H., Halliwell, B. (1976): The presence of glutathione and glutathione reductase in chloroplasts: a proposed role in ascorbic acid metabolism. - Planta 133: 21-25.

[26] Genty, B., Briantais, J. M., Baker, N. R. (1989): The relationship between the quantum yield of photosynthetic electron transport and quenching of chlorophyll fluorescence. BBA - General Subjects 990: 87-92.

[27] Giannopolitis, C. N., Ries, S. K. (1977): Superoxide dismutases: II. Purification and quantitative relationship with water-soluble protein in seedlings. - Plant Physiology 59: 315-318. 
[28] Gong, M., Li, Y. J., Chen, S. Z. (1998): Abscisic acid-induced thermotolerance in maize seedlings is mediated by calcium and associated with antioxidant systems. - J Plant Physiol 153: 488-496.

[29] Grennan, A. K., Ort, D. R. (2007): Cool temperatures interfere with D1 synthesis in tomato by causing ribosomal pausing. - Photosynthesis Research 94: 375-385.

[30] Grove, M. D., Spencer, G. F., Rohwedder, W. K., Mandava, N., Worley, J. F., Warthen, J. D., Steffens, G. L., Flippen-Anderson, J. L., Cook, J. C. (1979): Brassinolide, a plant growth-promoting steroid isolated from Brassica napus pollen. - Nature 28: 216-217.

[31] Guo, F. X., Zhang, M. X., Chen, Y., Zhang, W. H., Xu, S. J., Wang, J. H., An, L. Z. (2006a): Relation of several antioxidant enzymes to rapid freezing resistance in suspension cultured cells from alpine. - Cryobiology 52: 241-250.

[32] Guo, H. X., Liu, W. Q., Shi, Y. C. (2006b): Effects of different nitrogen forms on photosynthetic rate and the chlorophyll fluorescence induction kinetics of flue-cured tobacco. - Photosynthetica 44: 140-142.

[33] Gupta, N. K., Agarwal, V. P., Nathawat, N. S., Gupta, S. (2013): Effect of short-term heat stress on growth, physiology and antioxidative defence system in wheat seedlings. - Acta Physiologiae Plantarum 35: 1837-1842.

[34] Habap, D. L., Matal, D. L., Molina, E., Agüera, E. (2014): HT promotes early senescence in primary leaves of sunflo. - Revue Canadienne De Phytotechnie 94: 659-669.

[35] Hansen, J. R., Ruedy, R., Sato, M., Lo, K. (2010): Global Surface Temperature Change. Reviews of Geophysics 48: 103-110.

[36] Havaux, M., Tardy, F. (1996): Temperature-dependent adjustment of the thermal stability of photosystem II in vivo: possible involvement of xanthophyll-cycle pigments. - Planta 198: 324-333.

[37] Havir, E. A., Mchale, N. A. (1987): Biochemical and developmental characterization of multiple forms of catalase in tobacco leaves. - Plant Physiology 84: 450-455.

[38] He, B., Guo, T., Huang, H., Xi, W., Chen, X. (2017): Physiological responses of Scaevola aemula seedlings under HT stress. - South African Journal of Botany 112: 203-209.

[39] Huang, Z. (1982): The astrobiological characteristics and cultivation techniques of $M$. officinalis. - Subtropical Plant Science 11: 4-14.

[40] Janeczko, A., Okleštková, J., Pociecha, E., Kościelniak, J., Mirek, M. (2011): Physiological effects and transport of 24-epibrassinolide in heat-stressed barley. - Acta Physiologiae Plantarum 33: 1249-1259.

[41] Jin, B. (2011): The effect of experimental warming on leaf functional traits, leaf structure and leaf biochemistry in Arabidopsis thaliana. - Bmc Plant Biology 11: 35.

[42] Jumrani, K., Bhatia, V. S., Pandey, G. P. (2017): Impact of elevated temperatures on specific leaf weight, stomatal density, photosynthesis and chlorophyll fluorescence in soybean. - Photosynthesis Research 131: 1-18.

[43] Karlidag, H., Yildirim, E., Turan, M. (2011): Role of 24-epibrassinolide in mitigating the adverse effects of salt stress on stomatal conductance, membrane permeability, and leaf water content, ionic composition in salt stressed strawberry (Fragaria ananassa). Scientia Horticulturae 130 .

[44] Khanna-Chopra, R. (2012): Leaf senescence and abiotic stresses share reactive oxygen species-mediated chloroplast degradation. - Protoplasma 249: 469-481.

[45] Kochba, J., Lavee, S., Spiegelroy, P. (1977): Differences in peroxidase activity and isoenzymes in embryogenic and non-embryogenic 'Shamouti' orange ovular callus lines. - Plant \& Cell Physiology 18: 463-467.

[46] Kulaeva, O. N., Burkhanova, E. A., Fedina, A. B., Khokhlova, V. A., Adam, G. (1991): Effect of Brassinosteroids on Protein Synthesis and Plant-Cell Ultrastructure under Stress Conditions. - In: Cutler, H. G. et al. (eds.) Brassinosteroids. Chemistry, Bioactivity, and Applications. ACS Symposium Series. ACS, Washington, DC, pp. 141-155.

[47] Li, X., Wei, J. P., Ahammed, G. J., Zhang, L., Li, Y., Yan, P., Zhang, L. P., Han, W. Y. (2018): Brassinosteroids attenuate moderate HT-caused decline in tea quality by 
enhancing theanine biosynthesis in Camellia sinensis L. - Frontiers in Plant Science 9: 1016.

[48] Li, Y. F., Liu, Y. Q., Yang, M., Wang, H. L., Huang, W. C., Zhao, Y. M., Luo, Z. P. (2004): The cytoprotective effect of inulin-type hexasaccharide extracted from Morinda officinalis on PC12 cells against the lesion induced by corticosterone. - Life Sciences 75: 1531-1538.

[49] Lichtenthaler, H. K. (1987): Chlorophylls and carotenoids: pigments of photosynthetic biomembranes. - Methods in Enzymology 148C: 350-382.

[50] Lima, J. V., Lobato, A. K. S. (2017): Brassinosteroids improve photosystem II efficiency, gas exchange, antioxidant enzymes and growth of cowpea plants exposed to water deficit. - Physiol Mol Biol Plants 23: 59-72.

[51] Liu, G., Wu, R., Sun, S., Wang, H. (2015): Synergistic contribution of precipitation anomalies over northwestern India and the South China Sea to HT over the Yangtze River Valley. - Advances in Atmospheric Sciences 32: 1255-1265.

[52] Liu, G., Wu, R., Wang, H., Ji, L. (2017): Effect of tropical Indian Ocean thermal condition during preceding winter on summer HT anomalies over the southern Yangtze River valley. - International Journal of Climatology 37: 3478-3490.

[53] Mathur, S., Agrawal, D., Jajoo, A. (2014): Photosynthesis: response to HT stress. Journal of Photochemistry \& Photobiology B Biology 137: 116-126.

[54] Maxwell, K., Johnson, G. N. (2000): Chlorophyll fluorescence - a practical guide. Journal of Experimental Botany 51: 659-668.

[55] Mittler, R. (2002): Oxidative stress, antioxidants and stress tolerance. - Trends in Plant Science 7: 405-410.

[56] Nakano, Y., Asada, K. (1987): Purification of ascorbate peroxidase in spinach chloroplasts; its inactivation in ascorbate-depleted medium and reactivation by monodehydroascorbate radical. - Plant \& Cell Physiology 28: 131-140.

[57] Niu, S., Wan, S. (2008): Warming changes plant competitive hierarchy in a temperate steppe in northern China. - Journal of Plant Ecology 1: 103-110.

[58] Nogués, S., Baker, N. R. (2000): Effects of drought on photosynthesis in Mediterranean plants grown under enhanced UV-B radiation. - Journal of Experimental Botany 51: 1309-1317.

[59] Ogweno, J. O., Xing, S. S., Kai, S., Wen, H. H., Wei, H. M., Yan, H. Z., Jing, Q. Y., Nogués, S. (2008): Brassinosteroids alleviate heat-induced inhibition of photosynthesis by increasing carboxylation efficiency and enhancing antioxidant systems in Lycopersicon esculentum. - Journal of Plant Growth Regulation 27: 49-57.

[60] Patterson, B. D., MacRae, E. A., Ferguson, I. B. (1984): Estimation of hydrogen peroxide in plant extracts using titanium(IV). - Analytical Biochemistry 139: 487-492.

[61] Peng, J. B. (2014): An Investigation of the formation of the heat wave in southern China in summer 2013 and the relevant abnormal subtropical high activities. - Atmospheric \& Oceanic Science Letters 7: 286-290.

[62] Qu, T., Liu, R., Wang, W., An, L., Chen, T., Liu, G., Zhao, Z. (2011): Brassinosteroids regulate pectin methylesterase activity and AtPME41 expression in Arabidopsis under chilling stress. - Cryobiology 63: 111-117.

[63] Que, F., Khadr, A., Wang, G. L., Li, T., Wang, Y. H., Xu, Z. S., Xiong, A. S. (2018): Exogenous brassinosteroids altered cell length, gibberellin content, and cellulose deposition in promoting carrot petiole elongation. - Plant Sci 277: 110-120.

[64] Ramakrishna, B., Rao, S. S. R. (2012): 24-Epibrassinolide alleviated zinc-induced oxidative stress in radish (Raphanus sativus L.) seedlings by enhancing antioxidative system. - Plant Growth Regulation 68: 249-259.

[65] Ramakrishna, B., Rao, S. S. R. (2013): 24-Epibrassinolide maintains elevated redox state of AsA and GSH in radish (Raphanus sativus L.) seedlings under zinc stress. - Acta Physiologiae Plantarum 35: 1291-1320. 
[66] Roháček, K. (2002): Chlorophyll Fluorescence parameters: the definitions, photosynthetic meaning, and mutual relationships. - Photosynthetica 40: 13-29.

[67] Sasse, J. M. (2003): Physiological actions of brassinosteroids: an update. - Journal of Plant Growth Regulation 22: 276-288.

[68] Sayed, O. H. (2003): Chlorophyll fluorescence as a tool in cereal crop research. Photosynthetica 41: 321-330.

[69] Sayed, O. H., Earnshaw, M. J., Emes, M. J. (1989): Photosynthetic responses of different varieties of wheat to HTII. - Journal of Experimental Botany 40: 633-638.

[70] Sedigheh, H. G., Mortazavian, M., Norouzian, D., Atyabi, M., Akbarzadeh, A., Hasanpoor, K., Ghorbani, M. (2011): Oxidative stress and leaf senescence. - Bmc Research Notes 4: 477-477.

[71] Shamsul, H., Qaiser, H., Mohammed Nasser, A., Arif Shafi, W., John, P., Aqil, A. (2012): Role of proline under changing environments: a review. - Plant Signal Behav 7: 1456-1466.

[72] Shin, J. S., Yun, K. J., Chung, K. S., Seo, K. H., Park, H. J., Cho, Y. W., Baek, N. I., Jang, D. S., Lee, K. T. (2013): Monotropein isolated from the roots of M. officinalis ameliorates proinflammatory mediators in RAW 264.7 macrophages and dextran sulfate sodium (DSS)-induced colitis via NF- $\kappa$ B inactivation. - Food \& Chemical Toxicology 53: 263-271.

[73] Shu, S., Tang, Y., Yuan, Y., Sun, J., Zhong, M., Guo, S. (2016): The role of 24epibrassinolide in the regulation of photosynthetic characteristics and nitrogen metabolism of tomato seedlings under a combined low temperature and weak light stress. - Plant Physiology \& Biochemistry 107: 344-353.

[74] Silva, H. C. C. D., Asaeda, T. (2017): Effects of heat stress on growth, photosynthetic pigments, oxidative damage and competitive capacity of three submerged macrophytes. Journal of Plant Interactions 12: 228-236.

[75] Singh, I., Shono, M. (2005): Physiological and molecular effects of 24-epibrassinolide, a brassinosteroid on thermotolerance of tomato. - Plant Growth Regulation 47: 111-119.

[76] Stoyanova, D., Yordanov, I. (2000): Influence of drought, HT, and carbamide cytokinin 4-PU-30 on photosynthetic activity of plants. 2. Chloroplast ultrastructure of primary bean leaves. - Photosynthetica 37: 621-625.

[77] Sun, Z., P., Li, T., L., Liu, Y., L. (2011): Effects of elevated $\mathrm{CO}_{2}$ applied to potato roots on the anatomy and ultrastructure of leaves. - Biologia Plantarum 55: 675.

[78] Tang, Y., Wen, X., Lu, Q., Yang, Z., Cheng, Z., Lu, C. (2007): Heat stress induces an aggregation of the light-harvesting complex of photosystem II in spinach plants. - Plant Physiology 143: 629-638.

[79] Tarin, M. W. K., Fan, L., Shen, L., Lai, J., Li, J., Deng, Z., Chen, L., He, T., Rong, J., Zheng, Y. (2020a): Rice straw biochar impact on physiological and biochemical attributes of Fokienia hodginsii in acidic soil. - Scand. J. For. Res. 35(1-2): 59-68.

[80] Tarin, M. W. K., Fan, L., Tayyab, M., Sarfraz, R., Chen, L., He, T., Rong, J., Chen, L., Zheng, Y. (2019b): Effects of bamboo biochar amendment on the growth and physiological characteristics of Fokienia hodginsii. - Appl Ecol Environ Res 16: 80558074. https://doi.org/10.15666/aeer/1606_80558074.

[81] Thussagunpanit, J., Jutamanee, K., Kaveeta, L., Chai-Arree, W., Pankean, P., Homvisasevongsa, S., Suksamrarn, A. (2015a): Comparative effects of brassinosteroid and brassinosteroid mimic on improving photosynthesis, lipid peroxidation, and rice seed set under heat stress. - Journal of Plant Growth Regulation 34: 320-331.

[82] Thussagunpanit, J., Jutamanee, K., Sonjaroon, W., Kaveeta, L., Chai-Arree, W., Pankean, P., Suksamrarn, A. (2015b): Effects of brassinosteroid and brassinosteroid mimic on photosynthetic efficiency and rice yield under heat stress. - Photosynthetica 53: 312-320.

[83] Vasil'Ev, S., Wiebe, S., Bruce, D. (1998): Non-photochemical quenching of chlorophyll fluorescence in photosynthesis. 5-hydroxy-1,4-naphthoquinone in spinach thylakoids as a 
model for antenna based quenching mechanisms. - Biochim Biophys Acta 1363: 147156.

[84] Virginia, M., Ebi, K. L. (2012): IPCC special report on managing the risks of extreme events and disasters to advance climate change adaptation (SREX). - Journal of Epidemiology \& Community Health 66: 759.

[85] Wahid, A., Gelani, S., Ashraf, M., Foolad, M. R. (2007): Heat tolerance in plants: an overview. - Environmental \& Experimental Botany 61: 199-223.

[86] Wang, Z., Zheng, P., Meng, J., Xi, Z. (2015): Effect of exogenous 24-epibrassinolide on chlorophyll fluorescence, leaf surface morphology and cellular ultrastructure of grape seedlings (Vitis vinifera L.) under water stress. - Acta Physiologiae Plantarum 37: 1729.

[87] Wise, R. R., Olson, A. J., Schrader, S. M., Sharkey, T. D. (2010): Electron transport is the functional limitation of photosynthesis in field-grown Pima cotton plants at HT. - Plant Cell \& Environment 27: 717-724.

[88] Wu, X., Yao, X., Chen, J., Zhu, Z., Zhang, H., Zha, D. (2014): Brassinosteroids protect photosynthesis and antioxidant system of eggplant seedlings from high-temperature stress. - Acta Physiologiae Plantarum 36: 251-261.

[89] Wu, Z. Q., Chen, D. L., Lin, F. H., Lin, L., Shuai, O., Wang, J. Y., Qi, L. K., Zhang, P. (2015): Effect of bajijiasu isolated from Morinda officinalis F. C. how on sexual function in male mice and its antioxidant protection of human sperm. - Journal of Ethnopharmacology 164: 283-292.

[90] Xia, X., Huang, L., Zhou, Y., Mao, W., Shi, K., Wu, J., Tadao, A., Chen, Z., Yu, J. (2009): Brassinosteroids promote photosynthesis and growth by enhancing activation of Rubisco and expression of photosynthetic genes in Cucumis sativus. - Planta 230: 11851196.

[91] Yuan, L. Y., Du, J., Yuan, Y. H., Shu, S., Sun, J., Guo, S. R. (2013): Effects of 24epibrassinolide on ascorbate-glutathione cycle and polyamine levels in cucumber roots under $\mathrm{Ca}\left(\mathrm{NO}_{3}\right) 2$ stress. - Acta Physiologiae Plantarum 35: 253-262.

[92] Yue, J., You, Y., Zhang, L., Fu, Z., Wang, J., Zhang, J., Guy, R. D. (2019): Exogenous 24-epibrassinolide alleviates effects of salt stress on chloroplasts and photosynthesis in Robinia pseudoacacia L. seedlings. - Journal of Plant Growth Regulation 38: 669-682.

[93] Zhang, H., Li, J., Xia, J., Lin, S. (2013a): Antioxidant activity and physicochemical properties of an acidic polysaccharide from M. officinalis. - International Journal of Biological Macromolecules 58: 7-12.

[94] Zhang, J. H., Xin, H. L., Xu, Y. M., Shen, Y., He, Y. Q., Hsien-Yeh, Lin, B., Song, H. T., Juan-Liu, Yang, H. Y. (2018): M. officinalis How. - a comprehensive review of traditional uses, phytochemistry and pharmacology. - Journal of Ethnopharmacology 213: 230-255.

[95] Zhang, R., Wise, R. R., Struck, K. R., Sharkey, T. D. (2010): Moderate heat stress of Arabidopsis thaliana leaves causes chloroplast swelling and plastoglobule formation. Photosynthesis Research 105: 123-134.

[96] Zhang, R., Li, Q., Qu, M., Gao, J., Ma, W., Liu, W., Sun, T., Ding, P. (2016): Investigation on germplasm resources of Morinda officinalis. - Modern Chinese Medicine 18: 482-487.

[97] Zhang, Y. P., Zhu, X. H., Ding, H. D., Yang, S. J., Chen, Y. Y. (2013b): Foliar application of 24-epibrassinolide alleviates high-temperature-induced inhibition of photosynthesis in seedlings of two melon cultivars. - Photosynthetica 51: 341-349.

[98] Zhang, Y. P., He, J., Yang, S. J., Chen, Y. Y. (2014): Exogenous 24-epibrassinolide ameliorates HT-induced inhibition of growth and photosynthesis in Cucumis melo. Biologia Plantarum 58: 311-318.

[99] Zhao, G., Xu, H., Zhang, P., Su, X., Zhao, H. (2017): Effects of 2,4-epibrassinolide on photosynthesis and Rubisco activase gene expression in Triticum aestivum L. seedlings under a combination of drought and heat stress. - Plant Growth Regulation 81: 377-384. 
[100] Zheng, Y., Xu, M., Hou, R., Shen, R., Qiu, S., Ouyang, Z. (2013): Effects of experimental warming on stomatal traits in leaves of maize (Zea may L.). - Ecology \& Evolution 3: 3095-3111.

[101] Zhou, H. W., Zhang, H. Y., Wang, Z. H., He, C., You, L. L., Fu, D. H., Song, J. B., Huang, Y. J., Liao, J. L. (2019): Discovery of unique single nucleotide polymorphisms in rice in response to high nighttime temperature stress using a hybrid sequencing strategy. Environmental and Experimental Botany 162: 48-57.

[102] Zhu, M., Wang, C., Zhang, H., Pei, X. (2008): Protective effect of polysaccharides from M. officinalis on bone loss in ovariectomized rats. - International Journal of Biological Macromolecules 43: 276-278.

[103] Zuo, J. Q., Ren, H. L., Li, W. J., Wang, L. (2016): Interdecadal variations in the relationship between the winter North Atlantic oscillation and temperature in SouthCentral China. - Journal of Climate 29: 7477-7493.

[104] Zushi, K., Kajiwara, S., Matsuzoe, N. (2012): Chlorophyll a fluorescence OJIP transient as a tool to characterize and evaluate response to heat and chilling stress in tomato leaf and fruit. - Scientia Horticulturae 148: 39-46. 


\section{APPENDIX}

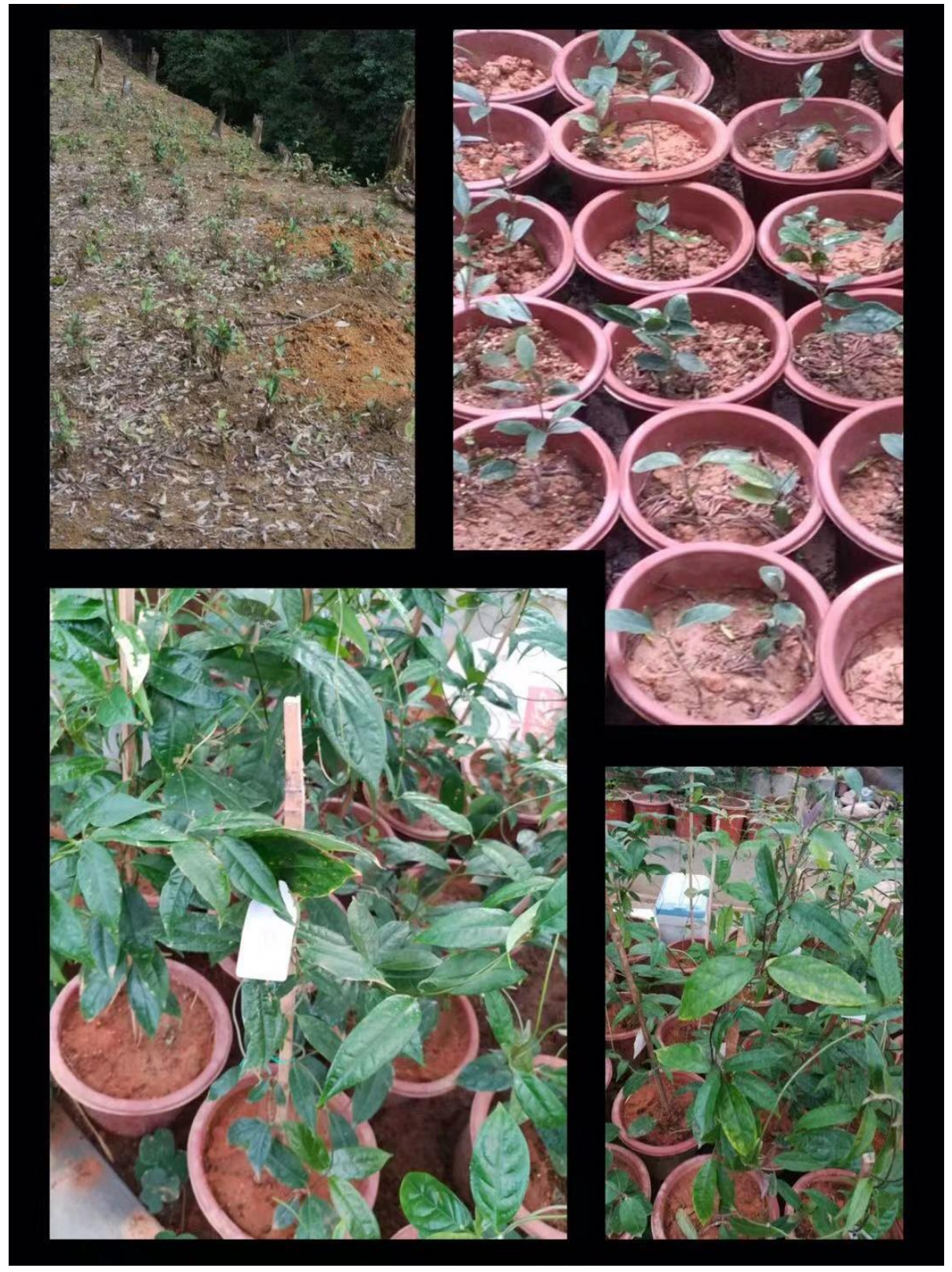

Figure A1. View of seedlings showing different stages of M. officinalis How., arranged in completely randomized design 